\title{
Palaeo- and archaeostomatopods (Hoplocarida, Crustacea) from the Bear Gulch Limestone, Mississippian (Namurian), of central Montana
}

\author{
Ronald A. Jenner, Cees H.J. Hof \& Frederick R. Schram \\ Institute for Systematics and Population Biology, University of Amsterdam, P.O. Box 94766, \\ 1090 GT Amsterdam, The Netherlands
}

Keywords: Malacostraca, Hoplocarida, Stomatopoda, phylogeny, Bear Gulch

\begin{abstract}
The palaeostomatopod crustacean Bairdops beargulchensis Schram \& Horner, 1978 (Malacostraca, Hoplocarida) from the Mississippian Bear Gulch Limestone is now seen as a taxonomic composite that arose from the confusion of specimens of two distinct hoplocarid species. These species are herein described as the palaeostomatopod Bairdops beargulchensis Schram \& Horner, 1978 and a new species of archaeostomatopod, Tyrannophontes acanthocercus. Tyrannophontes acanthocercus is quite distinct from the Pennsylvanian archaeostomatopod $\boldsymbol{T}$. theridion from the Essex fauna (Mazon Creek), with which it was originally compared. Bairdops beargulchensis is very similar to the Mississippian palaeostomatopod, B. elegans, from the Scottish Glencartholm fauna. A previously proposed synonymy of $B$, beargulchensis with $T$. theridion is therefore rejected. A preliminary restudy of the archaeostomatopods $T$. theridion and Gorgonophontes peleron, and the palaeostomatopods Perimecturus rapax and $P$. parki, reveals some newly recognized characters of those taxa and suggests some novel interpretations of hoplocarid evolution. A cladistic phylogenetic analysis of the Hoplocarida including the Paleozoic forms resolves the higher level relationships of the hoplocarids (palaeostomatopods, archaeostomatopods, aeschronectids, and unipeltatans).
\end{abstract}

\section{Introduction}

The Bear Gulch palaeo- and archaeostomatopods are part of an extensive invertebrate fauna of the late Mississippian (Namurian) Bear Gulch Limestone of central Montana. This Carboniferous Konservat-Lagerstätte preserves a near-shore marine community (Schram \& Horner, 1978; Factor \& Feldmann, 1985). In quality of preservation and species diversity, it is comparable to the Solnhofen Limestone of the Jurassic of Bavaria (Williams,
1983). This fauna in fact has yielded the largest and most diverse collection of Carboniferous vertebrates in the world. Prominent among the Bear Gulch invertebrates are some ten species of malacostracan crustaceans, five of which are Hoplocarida. The rest of the fauna consists of an extensive array of fish, conodonts, molluscs (cephalopods, gastropods and bivalves), brachiopods, annelids, xiphosurans, sponges and various unidentified, enigmatic groups (e.g., see Melton, 1969; Schram \& Horner, 1978; Factor \& Feldmann, 1985; Conway Morris, 1990).

The Bear Gulch Limestone beds are part of the Bear Gulch Member of the Heath Formation in the Big Snowy Group of central and eastern Montana. Other limestone beds and black shales comprise the remaining part of the Bear Gulch Member (Factor \& Feldmann, 1985). The Bear Gulch Limestone crops out on Potter Creek Dome (Fig. 1), approximately $50 \mathrm{~km}$ southeast of Lewistown in Fergus County, Montana. The exact age and stratigraphic relationships of the Bear Gulch Limestone have been the subject of some debate (see Williams, 1981 for a summary), but the fossils of Potter Creek Dome strongly suggest a late Chesterian (uppermost Mississippian) age (Fig. 2). The Bear Gulch Limestone was deposited in a low-energy, shallow, tropical marine environment, and the excellent preservation of the Bear Gulch fossils is perhaps the result of high sedimentation rates combined with low oxygen levels at the sediment-water interface (Williams, 1983; Factor \& Feldmann, 1985).

The Bear Gulch fauna, the Middle Pennsylvani- 


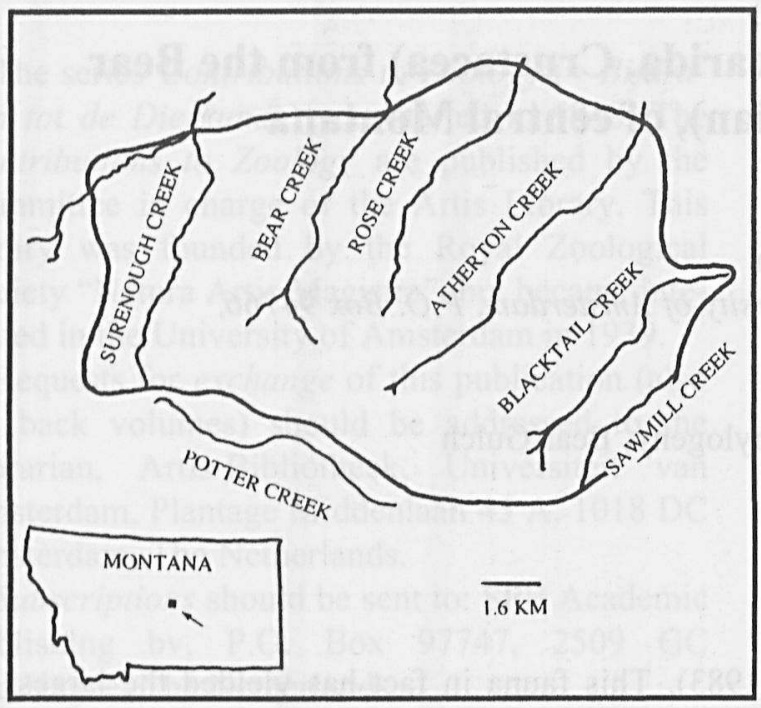

Fig. 1. Map showing the extent of the Bear Gulch Beds at Potter Creek Dome, Montana (modified from Williams, 1983).

an (Westphalian) Essex assemblage of the Mazon Creek region of Illinois, and the Viséan (Middle Mississippian) Glencartholm fauna from Scotland represent the three major Carboniferous Konservat-Lagerstätten (see Allison \& Briggs, 1991 for a more complete list of Phanerozoic Konservat-Lagerstätten). These Lagerstätten are well known for their exceptional preservation, which is reflected both in the exquisite quality of the fossils and their remarkable quantity, both in absolute numbers of organisms and taxonomic diversity (Briggs \& Clarkson, 1989, 1990).

One of the first endeavours to study evolutionary patterns utilizing data from Konservat-Lagerstätten in a systematic way, led to Schram's observation of a Carboniferous near-shore faunal continuum (Schram, 1979b). This Laurentian Carboniferous faunal continuum denotes the similarity in ecological and taxonomic composition of the near-shore marine fauna from Europe to North America, extending from at least the Viséan through the Westphalian. Briggs \& Gall (1990) showed that the concept of a continuum in transitional environments (near-shore to terrestrial) and the associated fauna can be extended from the late Paleozoic into the Mesozoic. The crustacean communities of the Bear Gulch fauna, the Essex fauna of the Mazon Creek and the Scottish Glencartholm fauna are part of a Carboniferous chronofauna and as such exhibit striking similarity in both ecologic structure and taxonomic composition (Schram, 1981). The pervasive ecologic and taxonomic stability of the near-shore crustacean communities at these three spatio-temporally distinct localities qualify them as the invertebrate analogue of a vertebrate chronofauna (Olson, 1966). Briggs \& Clarkson (1990) subsequently indicated that ecologic stability, as represented by the trophic structure (based on crustacean feeding types; Schram, 1981) of the various localities could not be maintained unambiguously. The maintenance of taxonomic stability through time, however, remains essentially unquestioned. The faunas at the different localities share genera or even species. Crangopsis eskdalensis is part of the Bear Gulch and Glencartholm faunas and Belotelson magister is present in both the Bear Gulch and Mazon Creek faunas.

As a consequence of their exceptional quality, data obtained from the study of Konservat-Lagerstätten should be approached with special care. Diversity studies can be distorted by the use of data from these kinds of faunas due to the large contrast in information content between the Lagerstätten and more typical fossil outcrops (Briggs \& Clarkson, 1990). The preservational quality of fossils from Lagerstätten can also strongly influence taxonomic practice when individual fossils with different preservational histories are to be compared. Problems arise when the taxa under comparison exhibit profound preservational differences. Personal preferences for the splitting of taxa or lumping them into a single taxon easily divide workers into camps of polarized interpretation. Similar problems have arisen in the taxonomic history of the Bear Gulch tyrannophontids.

\section{Taxonomic and phylogenetic background of the Hoplocarida}

The classification of the hoplocarids has been a story of continuous change since the early 1960s (Schram, 1986). Prior to 1962, only a limited array of extant and fossil stomatopods occurred within the order Stomatopoda Latreille, 1817. However, at present.the subclass Hoplocarida Calman, 1904 
is divided into three separate orders: Stomatopoda Latreille, 1817, Aeschronectida Schram, 1969, and Palaeostomatopoda Brooks, 1962. The order Stomatopoda is further subdivided into two suborders: Unipeltata Latreille, 1925 and Archaeostomatopodea Schram, 1969. The aeschronectids, palaeostomatopods and archaeostomatopods are represented exclusively by late Paleozoic forms.

Presently, at least 412 species within five superfamilies and 109 genera constitute the extant unipeltatan stomatopods (Manning, 1995). Their unambiguous fossil record goes back to the early Jurassic (Sinemurian). Except for the extinct Mesozoic family Sculdidae Dames, 1886, all unipeltatans can be accommodated within modern families. The taxonomy of the unipeltatan stomatopods has been in flux for at least the past thirty years. Much has been achieved since the Treatise on Invertebrate Paleontology (Holthuis \& Manning, $1969)$ recorded the 24 genera of unipeltatan stomatopods that were known at the time. Since then, substantial contributions to the description of extant and extinct unipeltatans have been and are being made. These developments, however, have not been paralleled by investigations into the phylogenetic relationships within the stomatopods (Hof, in press).

In 1962, H.K. Brooks erected the order Palaeostomatopoda to accommodate the genera Perimecturus Peach, 1908 and Archaeocaris Meek, 1872. Brooks listed the following features as characteristic of the Palaeostomatopoda: "Carapace shallow with articulated rostrum, four posterior thoracic somites freely articulated, thoracic somites [sic] two to five subchelate and subequal in size." (Brooks, 1962: 72). In 1969, Brooks' list of palaeostomatopodan characters differed somewhat from that of 1962 and was partially complementary to it: "Thoracopods subchelate, second to fifth pairs subequal, telson with fixed median spine and styliform furca." (Brooks, 1969: 535). In a series of papers, Schram $(1979 \mathrm{a}, 1979 \mathrm{c})$ re-evaluated the early work on palaeostomatopods, mainly that of Peach (1908) and Brooks (1962), removed much ambiguity caused by the substantial over-splitting of taxa (especially by Peach), and revised Brooks' descriptions of the species of Archaeocaris.

Peach (1908) had placed the genus Perimectu-

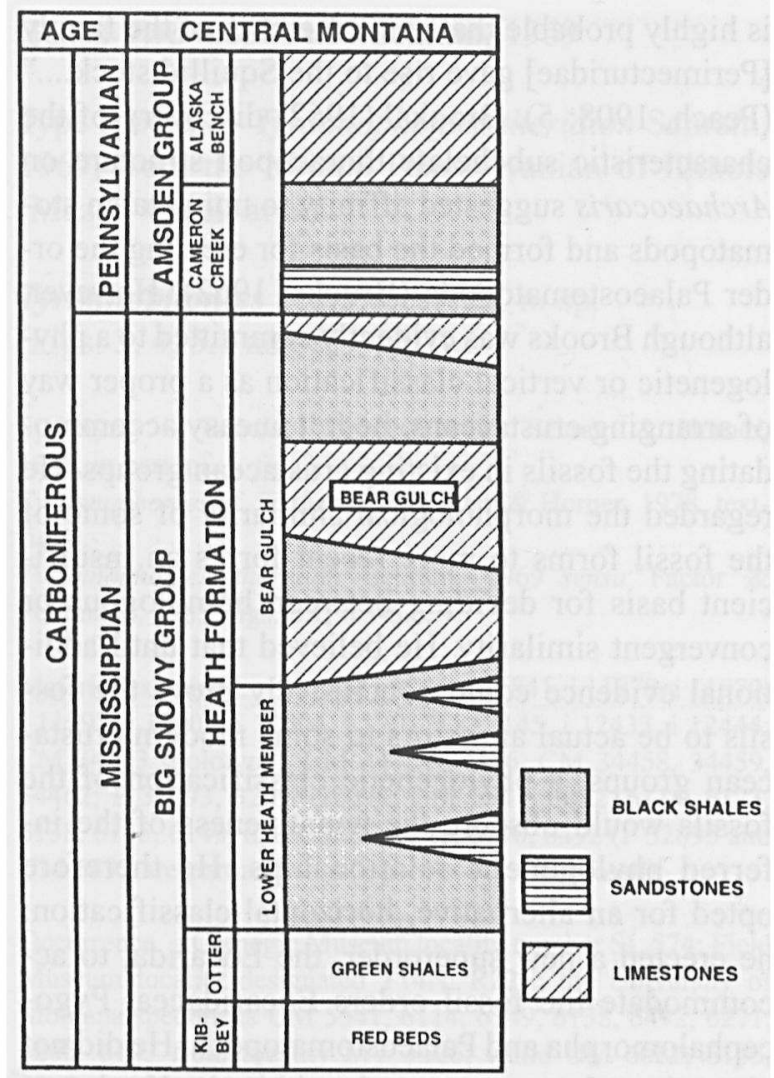

Fig. 2. Stratigraphic section of the mid-Carboniferous rocks of central Montana as exposed on Potter Creek Dome (modified after Williams, 1981).

rus in his "Mysid-group" which, combined with his "Euphausid-group", comprised the schizopods (Latreille, 1817). Of his six initially described species of Perimecturus, currently only Perimecturus parki (Peach, 1882) is retained in name, while the remaining species are subsumed in either this species or Bairdops elegans (Peach, 1908) (see Schram, 1979c). The single specimen of "Perimecturus" pattoni (Peach, 1908) does not allow for a definitive placement in any higher category and was therefore retained incerta sedis (Schram, 1979c).

The structure of the tail fan and the fact that all but the most anterior thoracic segments appeared free (not fused to the carapace) suggested to Peach (1908) close affinity of the perimecturids and gonodactyloids (especially Gonodactylus chiragra Fabricius, 1781). However, Peach was not certain about the exact relationship of the perimecturids and the modern forms, but he did remark that, ".....it 
is highly probable that some member of the family: [Perimecturidae] gave rise to the Squillid stock..." (Peach, 1908: 5). Brooks' (1962) discovery of the characteristic subchelate thoracopod structure on Archaeocaris suggested affinity to unipeltatan stomatopods and formed the basis for erecting the order Palaeostomatopoda (Brooks, 1962). However, although Brooks was evidently committed to a phylogenetic or vertical classification as a proper way of arranging crustaceans, he felt uneasy accommodating the fossils in existing crustacean groups. $\mathrm{He}$ regarded the morphological similarity of some of the fossil forms to more recent forms an insufficient basis for deciding between homologous or convergent similarity. He believed that until additional evidence could conclusively prove the fossils to be actual ancestors to some modern crustacean groups, a phylogenetic classification of the fossils would obscure the tentativeness of the inferred phylogenetic relationships. He therefore opted for an alternative, horizontal classification: he erected a new superorder, the Eocarida, to accommodate the fossil orders Eocaridacea, Pygocephalomorpha and Palaeostomatopoda. He did not place the palaeostomatopods within the Hoplocarida until 1969 (Brooks, 1969).

At present, six species within three genera (Perimecturus, Bairdops and Archaeocaris) are grouped within the Palaeostomatopoda (Schram, 1979a, 1986). The species of Perimecturus are characterized by their dorsoventrally flattened body and the distinct structure of their tail fans. Members of the genera Bairdops and Archaeocaris have more cylindrical bodies, but the greater complexity of the tail fans of Perimecturus and Bairdops sets these genera apart from Archaeocaris. The posteriorly reduced carapace of Archaeocaris apparently places it more closely to the archaeostomatopods than the other palaeostomatopod genera (Schram, 1979a).

Schram (1969) recognized the first species of Aeschronectida, Kallidecthes richardsoni Schram, 1969 and Aratidecthes johnsoni Schram, 1969, as well as the first archaeostomatopod Tyrannophontes theridion Schram, 1969. The aeschronectids diverged rather strikingly from the standard conception of hoplocaridan morphology, according to which hoplocarids are depicted as active, rapacious carnivores characterized by the presence of subchelate thoracopods (e.g., see Moore, 1969), in that the aeschronectids have "unmodified" (achelate) thoracopods. A variety of suggestions have emerged for the aeschronectid life-styles, viz., nektonic, epibenthic, filter feeding (Schram, 1986), detritus feeding (Briggs \& Clarkson, 1990), or omnivorous (Kunze, 1981).

The aeschronectids are placed within three families: Kallidecthidae Schram, 1969; Aenigmacarididae Schram \& Horner, 1978; Aratidecthidae Schram, 1979. The Kallidecthidae and Aenigmacarididae are distinguished by the possession of an elongated, stenopodous maxillary palp, subequal in length to the thoracopods. In addition, the aenigmacarids uniquely possess stenopodous pleopods. The aratidecthids do not carry an enlarged maxillary palp, but do possess an enlarged second antenna. Tyrannophontes theridion Schram, 1969 is not quite so specialized as unipeltatan stomatopods and was interpreted by Schram as a morphological intermediate between the palaeostomatopods and the unipeltatan stomatopods. The morphological intermediacy is particularly apparent from the structure of the thorax and the associated appendages. The combination of a regionalized thorax (divided into an anterior tagma of segments bearing subchelate thoracopods and a posterior tagma of larger "abdominalized" segments with locomotory limbs) and a posterior reduction of the carapace apparently links the archaeostomatopods more closely to the unipeltatan stomatopods than to the palaeostomatopods.

In 1978, Schram \& Horner described the malacostracan fauna from the Bear Gulch Limestone of central Montana, which included two new palaeostomatopod species and one tyrannophontid stomatopod of uncertain affinity. Schram \& Horner tentatively designated the small number of tyrannophontid remains they had at hand as Tyrannophontes of. T. theridion. In 1984, Schram revised some morphological details of $T$. theridion in comparison with the newly described archaeostomatopod Gorgonophontes peleron Schram, 1984. This revision tended to emphasize the overall similarity of T, theridion from the Mazon Creek and the Bear Gulch tyrannophontid.

However, the Bear Gulch hoplocarids were re- 
evaluated by Factor \& Feldmann (1985) on the basis of then new material. Factor \& Feldmann concluded that the palaeostomatopod Bairdops beargulchensis was a junior synonym of Tyrannophontes theridion. Our re-examination of the specimens they used reveals that most of what they had at hand for their study was in fact material of a true tyrannophontid and not $B$. beargulchensis at all. Furthermore, their synonymy actually hinges on a doubtful premise: their equation of the Mazon Creek T. theridion Schram, 1969 with the tyrannophontid from the Bear Gulch. The differences between the Mazon Creek and Bear Gulch tyrannophontids cannot be ascribed to the vagaries of preservation. These specimens represent different species altogether.

We have now studied previously undescribed archaeostomatopod fossils from the Bear Gulch Limestone acquired by the Museo Civico di Storia Naturale, in Milan (Italy). In addition, we have reexamined the palaeo- and archaeostomatopod fossils used for the original description of Bairdops beargulchensis, Tyrannophontes of. $T$. theridion (Schram \& Horner, 1978) and those used for the construction of the revised concept of Tyrannophontes theridion (Factor \& Feldmann, 1985). First, the Bear Gulch Tyrannophontes can now be seen as a distinct taxon from the Mazon Creek $T$. theridion. Second, Bairdops beargulchensis Schram \& Horner, 1978 was a composite derived from confusing specimens of a genuine palaeostomatopod and an archaeostomatopod from the Bear Gulch Limestone. Thus $B$. beargulchensis is neither a junior synonym of the Bear Gulch tyrannophontid, nor T. theridion.

\section{Systematic description}

The specimens used in this study are deposited in the Field Museum of Natural History, Chicago (P), Museum of Paleontology, University of Montana, Missoula (UM), Carnegie Museum of Natural History, Pittsburgh (CM), and the Museo Civico di Storia Naturale, Milan (Italy) (MSNM).

Subclass Hoplocarida Calman, 1904

Order Stomatopoda Latreille, 1817

Suborder Archaeostomatopodea Schram, 1969

Family Tyrannophontidae Schram, 1969
Genus Tyrannophontes Schram, 1969

Type species. - Tyrannophontes theridion Schram, 1969, from the Middle Pennsylvanian of Illinois (Mazon Creek area).

\section{Tyrannophontes acanthocercus, $\mathrm{n} . \mathrm{sp}$.}

(Figs. 3, 4, 5.1 and Pls. I-III)

Synonymy. - Bairdops beargulchensis Schram \& Horner, 1978, in part, pl. 1, fig. 3.

Tyrannophontes of. $T$, theridion Schram \& Horner, 1978, textfig. 5 .

Tyrannophontes theridion Schram, 1969 sensu Factor \& Feldmann, 1985, figs. 6.1, 6.3-6.6, 7 .

Material examined. -MSNM 1 8785, i 11841, i 11978, i 11979. i 11997, i 12002, i 12004, i 12017, i 12145, i 12433, i 12444; CM 34453 (holotype), CM 34454-34456, CM 34458, 34459, 34462; P 32093, 32095-32098; UM 5541, 6022, 6114, 6123, $6138,6145,6149,6205,6267,6271,6290,6492$ (P 32095 and UM 6492 are part and counterpart of the same fossil).

Occurrence. - Carnegie Museum locality number SL 574; Field Museum locality designated T14N, R22E; the University of Montana specimens UM 5541, 6114, 6149, 6138, 6492, 6271, 6205,6123 from locality MV 7106; while UM 6022, 6145, 6267 are recorded from site MV 7001; exact locality UM 6290 unknown; the exact locality within the Bear Gulch area of the Italian material is unknown.

Diagnosis. - Tyrannophontid stomatopod. Carapace extends mid-dorsally to the level of fifth thoracomere. Propodi of subchelate thoracopods with two parallel, submedian rows of unequally sized spines; one row of large, moveable spines on outer side and one row of smaller spines on inner side of median longitudinal plane of propodus. Pleura of exposed thoracomeres and pleomeres with anteroventral furrow and ridge, ridge passes into posteriorly directed anteroventral spine on pleomeres three to six. Pair of dorsal, submedian ridges present on sixth pleomere, in line with two processes projecting posteriorly from posterior margin of sixth pleomeral tergite beyond anterior telson margin. Uropodal protopod with dorsal process projecting posteriorly over exopod, and larger ventral process projecting posteriorly under endopod. Uropodal rami broadly blade-like with setae mounted on endopod and inner margin of exopod. Articulated spines mounted on approximately distal four fifths of outer margin of uropodal exopod. 
Robust telson with subrectangular base tapering off to terminal median spike flanked by four pairs of submedian spines decreasing in size with increasing distance from median spike. Median crest on telson defined by two submedian and one median carina.

Description. - The body length ranges between 2 and $8 \mathrm{~cm}$ (MSNM i 11979 and CM 34459 respectively).

The antennules are triflagellated with the annulated flagella (PI. I-2) subequal in length (MSNM i 11978). At least two robust peduncular segments are visible (CM 34455, CM 34453) (Pl. I-1). The antennae are directed ventrad and their peduncles have at least two elongated slender segments (CM 34453, CM 34458, UM 6149) (Pl. I-1, 2). A large subovate ventrolaterally directed scaphocerite is noted (P 32096) almost one third as broad as long. This scale widens from a narrow base to a rounded tip and setae are present along the margins (UM 6022, UM 6149) (Pl. I-2, 3). The scaphocerite of UM 6149 is composed of a small basal segment followed by a large flap-like scale (PI. I-2). The compound eyes are oval or reniform (CM 34453, MSNM i 12002b) (Pl. I-1). Ocular peduncles are not clearly preserved.

The heavily sclerotized mandibles are impressed through the carapace and are located at approximately three fifths of the length of the carapace from the posterior carapace margin (CM 34454) (Pl. I-4). The mandibles mainly consist of a large and massive mandibular body with a convex posterior margin and a narrow dorsal tip (Fig. 3).At least the dorsalmost part of the anterior margin is concave (CM 34454, CM 34458) with the curvature changing more ventrally. The margins of the mandibular body are relatively heavily sclerotized ridges surrounding a less distinct central body. The ventral portion of the mandible shows indications of a posteroventrally directed incisor process (CM 34454 , UM 6492, i 12444) and a slight anteriorly or anterodorsally directed molar process (CM 34454, UM 6492).

The carapace is subtriangular in lateral aspect, only slightly longer than high. In dorsal view, the carapace is approximately halfway between subtriangular and subrectangular in form with the dor- solateral carapace margins slightly converging anteriorly. Mid-dorsally, the carapace extends approximately to the anterior margin of the fifth thoracomere, while the lateral wings extend posteriad approximately to the anterolateral margin of the sixth thoracomere (MSNM i 11841b, MSNM i 12145) (P1. I-1). The carapace encloses the anterior thorax both dorsally and laterally. A furrow is present along the entire carapace margin. The dorsal surface of the carapace is slightly convex. The posterior carapace margin in lateral view is sigmoid, with a concave dorsal region and a convex ventrolateral corner. Based on the absence of a carapace on some specimens and the distinct and unfused nature of, at least, thoracomeres three through eight (MSNM i 12145, P 32095), we conclude that the carapace is free from all but the anteriormost thoracomeres. The articulated rostrum is smooth and flattened in lateral aspect (CM 34458, CM 34454) (Pl. I-4) and subtriangular in dorsal view. In dorsal aspect, the broad rostral base tapers into a more narrow, rounded tip (MSNM i 11853, MSNM i 11841b, MSNM i 12433a, MSNM i 12002a, UM 6149) (PI. I-2). The rostrum is about one fourth as long as the mid-dorsal length of the carapace and approximately one and a half times as long as broad.

The thorax is divided into two distinct tagmata: an anterior region of small but distinct and unfused segments (at least thoracomeres two to five) (Pl. I5) bearing subchelate thoracopods, and a posterior area of larger segments (thoracomeres six to eight). Specimens MSNM i 12002, MSNM i 11997, MSNM i 12017 and especially MSNM i 12145 and P32095 (P1. I-5) indicate the unfused and distinct appearance of the anterior thoracomeres. MSNM $i$ $1184 \mathrm{lb}$ preserves the unfused sternites of the anterior thoracomeres. The thoracomeres of the anterior tagma exhibit an anterior deflection of their pleu$\mathrm{ra}$ and the anterior thoracomeres are not as high, or deep, as those more posterior. Consequently, the cephalothorax tapers anteriorly while the sternites of the anteriormost thoracomeres show an anterior shift relative to the position of the tergites (MSNM i 12145, MSNM i 12017, MSNM i 11997, CM 34454) (PI. I-4). The pleurae of the exposed thoracomeres are rounded ventrally and have an anteroventral marginal furrow and ridge (Pl. I-1). The 

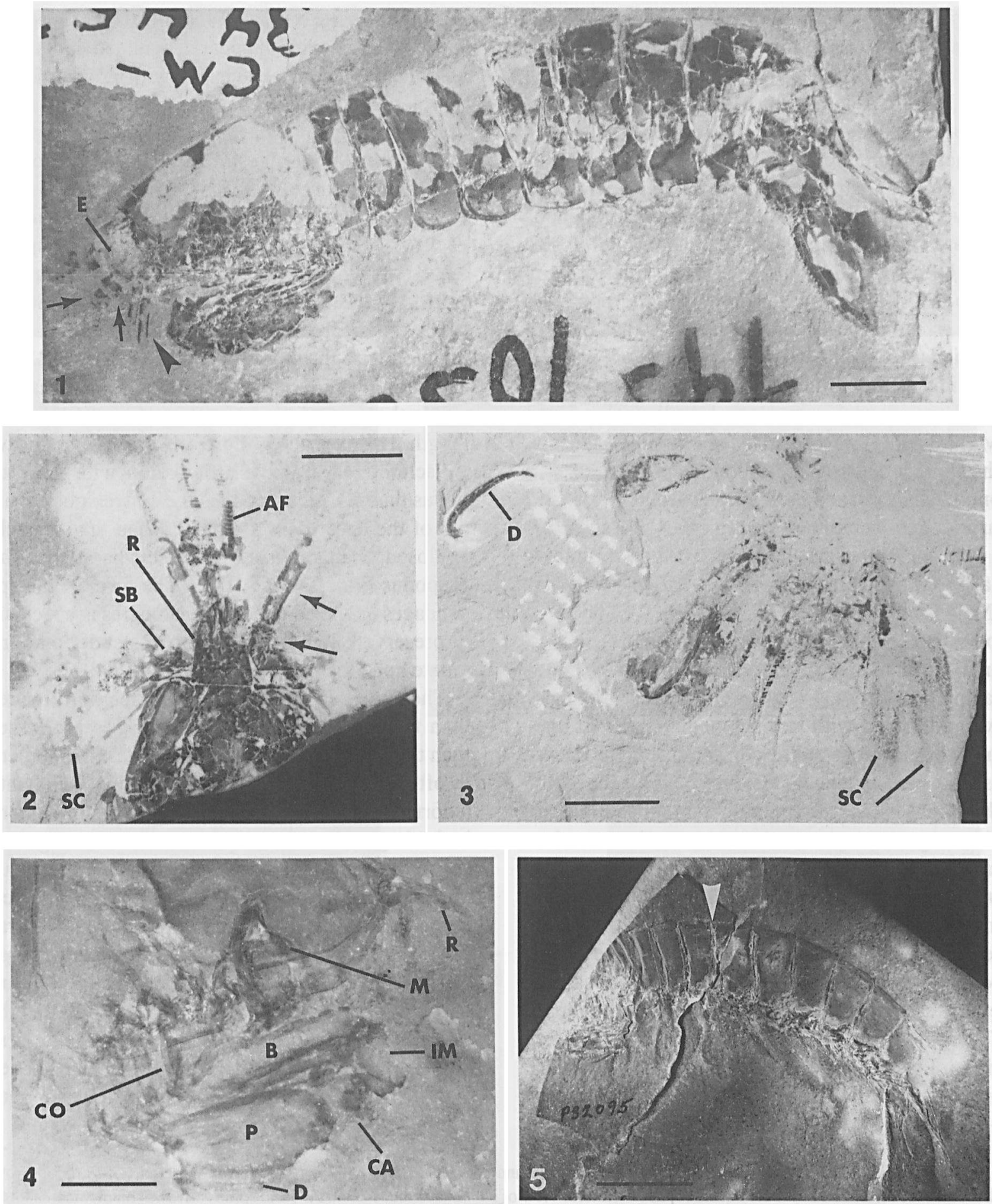

Pl. I. Tyrannophontes acanthocercus n. sp.; 2 and 4 photographed under water: 1 , holotype: CM 34453, lateral view, note broad peduncular segments of antennules (arrows) and slender peduncular segment of antenna (arrowhead), scale bar $=0.75 \mathrm{~cm} ; 2, \mathrm{UM}$ 6149 , dorsal view of anterior cephalothorax with cephalic appendages, note slender peduncular segments of antenna (arrows), scale bar $=0.3 \mathrm{~cm} ; 3$, UM 6022 , distorted cephalic appendages and subchelae, scale bar $=0.8 \mathrm{~cm} ; 4, \mathrm{CM} 34454$, lateral view of cephalothorax, anterior to right, scale bar $=0.2 \mathrm{~cm} ; 5, \mathrm{P} 32095$, lateral view showing the size difference of the anterior and posterior thoracomeres, arrowhead $=$ abdomen - thorax transition, scale bar $=1.6 \mathrm{~cm} . \mathrm{AF}=$ antennular flagellum, $\mathrm{B}=$ basis, $\mathrm{CA}=$ carpus, $\mathrm{CO}=$ coxa, $\mathrm{D}=$ dactylus, $\mathrm{E}=$ eye, $\mathrm{IM}=$ ischiomerus, $\mathrm{M}=$ mandible, $\mathrm{P}=$ propodus, $\mathrm{R}=$ rostrum, $\mathrm{SB}=$ scaphocerite basal segment, $\mathrm{SC}=$ scaphocerite. 
pleura of the sixth thoracomere tapers more sharply than that of the seventh and eighth thoracomere (CM 34453, MSNM i 12004, MSNM i 12444) (PI. I-1). No tergal decoration is present on the thoracomeres.

There is no indication of the structure of appendages on the first thoracomere. Thoracomeres two to five each bear a pair of subchelate thoracopods that are similar in appearance and subequal in size (Pls. I-1, 3, 4, II-1, 2 and III-1). The anterior pairs are positioned more laterally than the posterior pairs as indicated by the coxal holes that diverge anteriad (MSNM i 11841, UM 6271) (see Fig. 5.1). The rims on the sternites surrounding the holes into the thoracopodal coxae are heavily sclerotized (MSNM i 1 1841, CM 34454) (Pl. I-4 and Fig. 5.1). The thoracopods have a moderately sized coxa, a long basis, followed by a shorter ischiomerus and carpus. The ischiomerus and carpus are subequal in size and somewhat more robust than the proximal segments (MSNM i 11978, MSNM i 12444, CM 34454, UM 6138, UM 6492) (Pl. I-4). The propodus is subrectangular, being two and a half to three times longer than wide, with convex upper (facing the dactylus) and lower margins. It is massive and armed with two submedian rows of unequally sized spines on the surface facing the dactylus that may extend somewhat beyond the point where the distalmost tip of the dactylus aligns itself along the propodus. A furrow on the outer lateral surface of the propodus runs parallel to the longitudinal axis of the propodus. A row of small, fine and closely apposed spines is positioned on the inside of the median longitudinal plane of the propodus, while a row of larger spines appears to be located on the outside of this plane. The larger of these consists of two classes of unequally sized spines. The six or seven regularly spaced largest spines alternate with more numerous smaller spines
(CM 34456, MSNM i 12145) (Pl. II-3). These two types of large spines appear articulated and moveable. They are conically shaped with a robust, heavily sclerotized rounded base tapering to a thin, sharp tip. The large spines are not more widely spaced than the smallest spines. The wide spacing of the apices of the large spines is the result of the form of the robust bases that are in close apposition to each other. When disarticulated, the large spines leave cup-shaped sockets on the propodal surface (MSNM i 12145, CM 34453, CM 34456). Sometimes the disarticulated spines are found in conjunction with the empty sockets (MSNM i 12145). The thin, blade-like dactylus curves somewhat towards the propodus and is about four-fifths of its length. The dactylus is more robust and more heavily sclerotized near the articulation with the propodus than it is distally, as is the convex outer margin of the dactylus ( $P$ 32095). When the subchela is closed, the dactylus aligns itself parallel to the propodus (Pls. II-1 and III-1). The form of the appendages on the posterior thoracomeres is not clearly preserved. Indications point to slender and annulate appendages (CM 34459, UM 6492).

The abdomen is approximately one third longer than the cephalothorax. All pleomeres are larger than the thoracomeres. However, the first pleomere is often the smallest of the abdominal segments (shortest dorsal margin), while the sixth pleomere is the largest as a consequence of possessing dorsal, posteriorly directed tergal processes. The pleurae are subquadrate in lateral aspect with rounded corners. They are decorated with an anteroventral marginal furrow and ridge (Pl. II-4). The ridge passes into a posteriorly directed anteroventral spine on pleomeres three to six (Pl. II-2, 4). The height of the pleomeres decreases posteriorly, the first three pleomeres generally being higher or deeper than the last three pleomeres. The sixth pleomere

Pl. II. Tyrannophontes acanthocercus n. sp.; 3-6 photographed under water: 1, UM 6492, lateral view (counterpart of Pl. I-5), arrow indicating subchela, scale bar $=1.75 \mathrm{~cm} ; 2, \mathrm{P} 32093$, lateral view of subequal subchelae and pleural spines (arrows) on pleomeres three to $\mathrm{six}$, scale bar $=1.2 \mathrm{~cm} ; 3, \mathrm{CM} 34456$, lateral view of propodus spines, arrows indicate large spines, scale bar $=0.35 \mathrm{~cm} ; 4, \mathrm{MSNM}$ i 12004, lateral view of pleural spines (arrows) on pleomeres three through five, scale bar $=0.15 \mathrm{~cm} ; 5$, MSNM i 11841a, dorsal view of sixth pleomere and telson, note processess on sixth pleomere (arrows), scale bar $=0.16 \mathrm{~cm} ; 6, \mathrm{CM} 34459$, lateral view of pleopod on first pleomere, note anteroventrally directed spines (arrows), scale bar $=0.14 \mathrm{~cm} . \mathrm{AM}_{4}=$ anterior margin of pleomere $4, \mathrm{CA}=\mathrm{carpus}$, $D=$ dactylus, $D R=$ diagonal ridge, $I R=$ inner ramus of pleopod, $O R=$ outer ramus of pleopod, $P_{3,4,6}=$ pleomere 3,4 or $6, P D S=$ posterodorsal spine, $\mathrm{PM}_{3}=$ posterior margin of pleomere $3, \mathrm{PVS}=$ posteroventral spine, $\mathrm{Pr}=$ propodus, $\mathrm{S}=$ small spines, $\mathrm{T}=$ telson, $\mathrm{Th}$ $=$ thoracopod, $\mathrm{VM}=$ ventral margin of pleomere. 

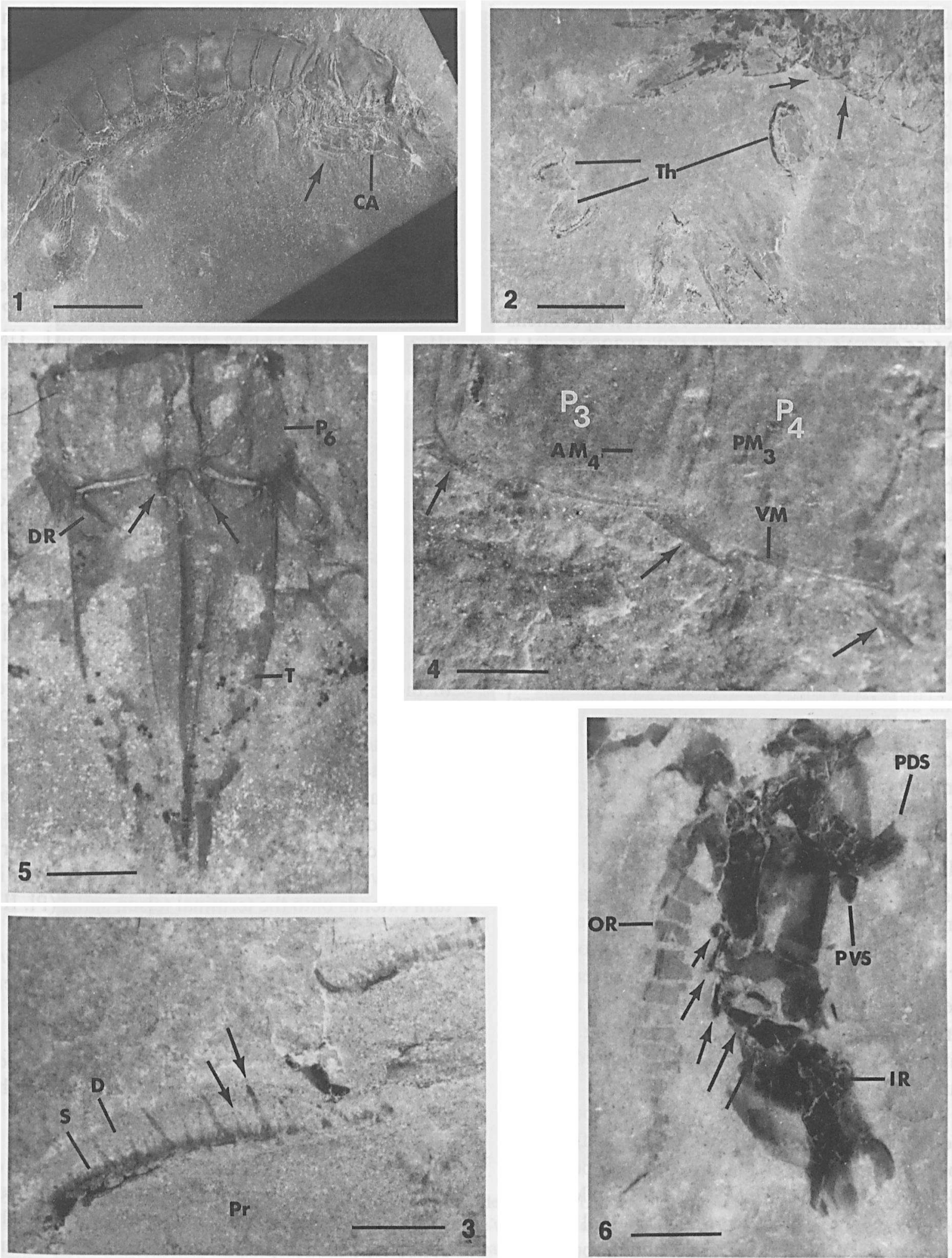
has a pair of dorsal, longitudinal submedian ridges. They are in line with two processes projecting posteriorly from the posterior margin of the tergite beyond the anterior margin of the telson (MSNM $i$ 11841a) (Pl. II-5). In lateral view, these processes appear as a single, dorsal, posteriorly directed process (MSNM i 12004, MSNM i 12145, CM 34453, $P$ 32095). No further tergal decoration is present on the pleomeres.

The abdominal sternites are undecorated and show large coxal holes indicating the size of the pleopodal protopods (MSNM i 11841b). Specimens UM 5541, CM 34455, CM 34459, P 32095 and P 32096 indicate the presence of massive, heavily sclerotized pleopods. CM 34459 preserves the first pleopod in detail (PI. II-6). The limb is biramous and has a massive single-segment protopod. A possible protopodal spine projects posterodorsally from the posterior margin of the protopod. A smaller ventrally directed process seems to protrude from the posteroventral corner of the protopod. This latter process is located more towards the median plane of the body than the rest of the protopod. The slender ramus probably represents the outer ramus. It consists of at least fifteen annulated segments. This annulated ramus can be detected on several specimens (Pls. II-6 and III-1). The inner ramus is more heavily sclerotized, robust and lobate. The rami are subequal in length. The anterior margin of the inner ramus on CM 24459 shows indications of five anteroventrally directed spines. The two distalmost spines appear to be twisted laterally on the specimen, together with the anterodistal part of the ramus. The exact segmentation of the inner ramus is not clear. The proximal part appears to consist of an anterior and a somewhat larger posterior segment. A single large, apparently undivided segment forms the distal part of the ramus (see Fig. 4). The anteroventrally directed spines are located on the anterior margin of this segment.

The uropods have single-segment protopods with a dorsal process projecting posteriorly from the posterior margin over the uropodal exopod (CM 34454, MSNM i 12145, MSNM i 12002, MSNM i 11841). A larger ventral process or basal prolongation projects posteriorly under the uropodal endopod (UM 6149) (Pl. III-2). The uropodal rami are unisegmental and broadly blade-like to lobate in outline (PI. III-3, 4). The uropodal endopod and the inner margin of the exopod are decorated with long delicate setae (P1. III-4). The outer part of the uropodal exopod is more heavily sclerotized than its inner part and the endopod. The heavily sclerotized outer half of the exopod is divided in a thickened narrow marginal ridge and a flattened median part. The entire sclerotized outer portion is separated from the more membranous inner part by a furrow (CM 34455, CM 34453) (Pl. III-4). Approximately the distal four fifths of the outer margin of the exopod bears articulated spines (P1. III-4) (CM 34455, CM 34453, UM 5541, UM 6205).

The telson is robust with a subrectangular base tapering to a terminal median spike that is between one fourth and one fifth the length of the telson base (P1. III-5). The terminal spike is flanked by four pairs of moveable submedian spines that decrease in size with increasing distance from the median spike (MSNM i 12433) and that are slightly curved towards the median spike. The pair of smallest spines may be unmoveable. From each anterolateral corner of the telson a sclerotized diagonal ridge of approximately one sixth the length of the telson base extends obliquely mesiad over the dorsal surface (i 11841a) (PI. II-5). The telson is ornamented by five longitudinal carinae: one pair of sublateral, one pair of submedian, and one dorso-median. The submedian and the dorso-median carinae define an elevated area on the telson, the median crest. The sublateral and submedian carinae converge upon the dorso-median carina that in turn extends onto the terminal telson spike (P1. III$3,5)$.

Fig. 4 shows a reconstruction of Tyrannophontes acanthocercus and its tail fan. Table I offers some representative measurements.

Etymology. - Combination of the Greek akanthos (thorn, prickle) and kerkos (tail), referring to the spined telson.

Remarks. - In the original study of Schram \& Horner (1978) the tyrannophontid they recognized was among the rarer faunal elements present in the collections made up until that time. Thus their uncertainty as to the taxonomic affinity of the specimens. It now turns out, after many more years of 

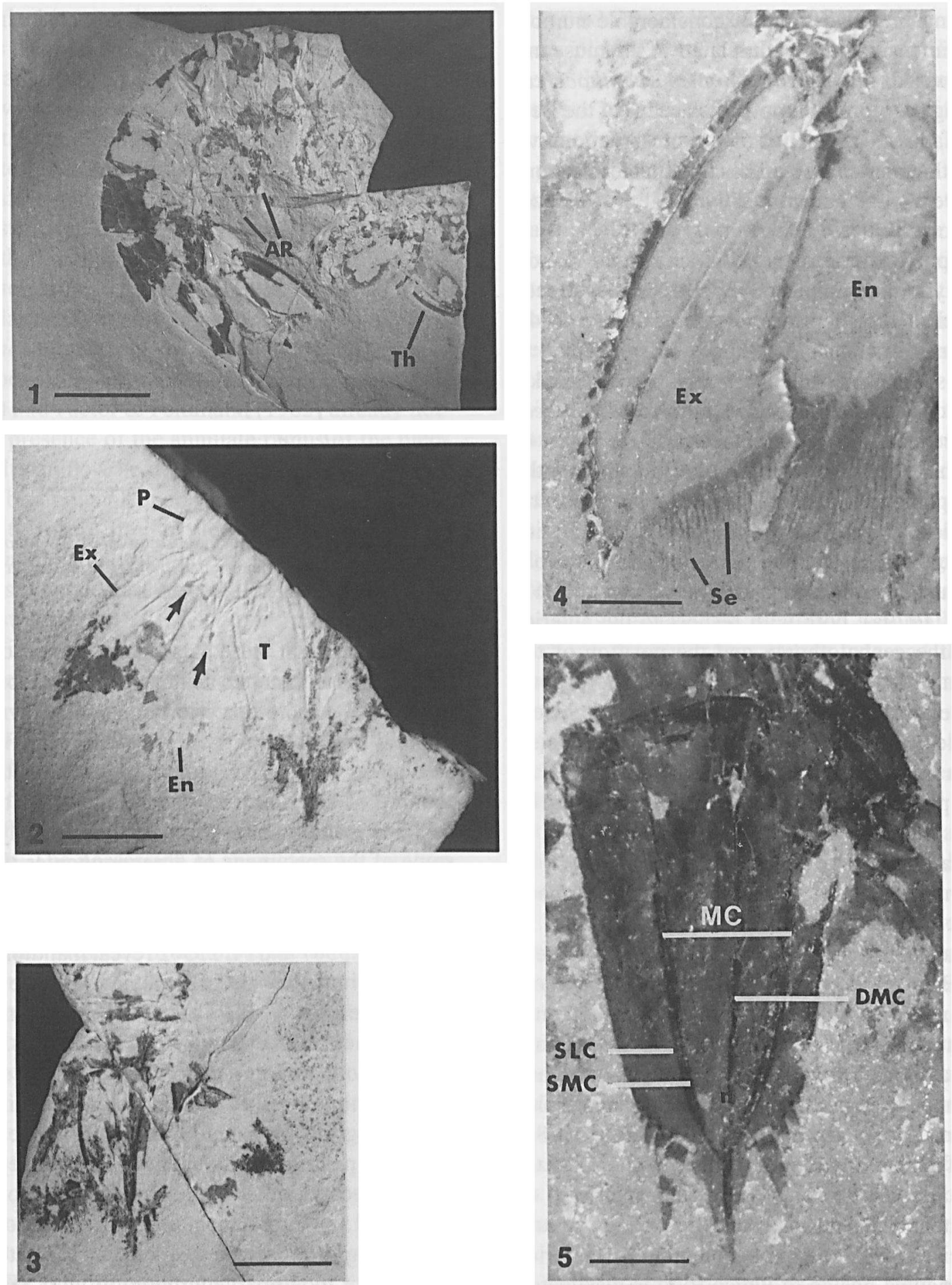

Pl. III. Tyrannophontes acanthocercus n. sp.; 4, 5 photographed under water: 1 , UM 5541, lateral view with the anterior curved to the right, scale bar $=1.2 \mathrm{~cm} ; 2, \mathrm{UM} 6149$, ventral view of partial tailfan with dorsal and ventral processes on uropodal protopod (arrows), scale bar $=0.35 \mathrm{~cm} ; 3$, UM 6149, dorsal view of partial tailfan" (part of III-2), scale bar $=0.58 \mathrm{~cm} ; 4$, CM 34455, lateral view of uropodal rami, scale bar $=0.2 \mathrm{~cm} ; 5$, MSNM i $12433 \mathrm{a}$, dorsal view telson, scale bar $=0.18 \mathrm{~cm}$. AR $=$ annulate or outer ramus of pleopod, $\mathrm{DMC}=$ dorsomedian carina, $\mathrm{En}=$ endopod of uropod, $\mathrm{Ex}=$ exopod of uropod, $\mathrm{MC}=$ median crest, $\mathrm{P}=$ protopod of uropod, $\mathrm{Se}=$ setae, $\mathrm{SLC}=$ sublateral carina, $\mathrm{SMC}=$ submedian carina, $\mathrm{T}=$ telson, $\mathrm{Th}=$ thoracopod. 
collecting in the area and a considerable number of specimens having accumulated in the museums of the world, that Tyrannophontes acanthocercus is among the more common crustaceans of the Bear Gulch fauna. The quality of the preservation evident in these strata also makes this species now one of the best known anatomically of all the Paleozoic hoplocarids.

The preservation of heavily sclerotized mandibles in tyrannophontid stomatopods has never been reported in the literature (Schram, 1969; 1984), while among palaeostomatopods it is confined to the two species of the genus Archaeocaris (Brooks, 1962; Schram, 1979a). The mandibles of Archaeocaris seem to be closer to the anterior margin of the cephalothorax as well as farther away from the thoracopod protopods than are the tyrannophontid mandibles. The mandibles of the tyrannophontids appear to be located more posteriorly in the cephalon than those of Archaeocaris (Brooks, 1962; Schram, 1979a), both with respect to the anterior part of the cephalothorax and the position of the proximal thoracopod segments. Structurally, however, the tyrannophontid mandible (Fig. 3) closely resembles the mandible of Archaeocaris, consisting of a large mandibular body bearing at least an incisor process for mastication. As pointed out by Brooks (Brooks, 1962), this mandibular form is comparable to that of unipeltatan stomatopods. In addition, the mandibles of unipeltatan stomatopods possess a molar process.

The uncertain identification of a molar process in the Bear Gulch tyrannophontids raises important issues concerning the evolution of the stomatopod mouth field. The unipeltatan stomatopods are unique among large-food feeding malacostracans in having a large molar process on the mandibles extending into the proventriculus (Kunze, 1981, 1983). This feature is part of a series of specializations that characterizes the feeding apparatus of unipeltatans. The posterior position of the mouth is associated with the enlargement of the anterior proventriculus, inside of which food is masticated by the molar processes of the mandibles. As observed above, the position of the mandibles in $\mathrm{Ar}$ chaeocaris indicates that the mouth is not so markedly displaced posteriad, and the apparent lack of the development of a mandibular molar process

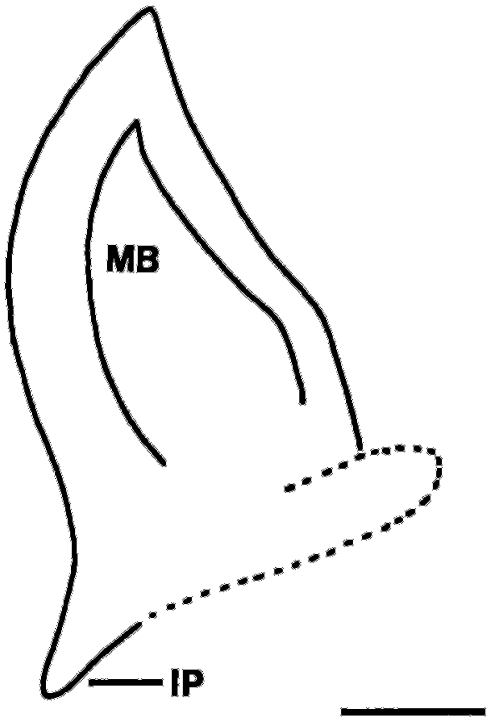

Fig. 3. Reconstruction of the mandible of Tyrannophontes acanthocercus $\mathrm{n}$. sp. (anterior to the right), scale bar $=0.85$ $\mathrm{mm} . \mathrm{IP}=$ incisor process, $\mathrm{MB}=$ mandibular body.

may indicate that these palaeostomatopods did not possess the distinctive feature of a large proventriculus. The more posteriorly positioned tyrannophontid mandibles and the tentative identification of a molar process could possibly indicate the beginning of an enlarged proventriculus and the associated mandibular apparatus. Further analysis of some of the specimens of Tyrannophontes theridion used for the original description of the species by Schram (1969) partially confirms this. Specimens PE 25507 and PE 25502 reveal mandibles and show the impression of a large and massive jaw.

However, we wish to stress the provisional nature of these observations for two reasons. First, study of other tyrannophontid specimens should provide more conclusive evidence concerning the morphology of the mandibular molar process and the exact position of the mandible in the cephalothorax. Second, other hoplocaridan taxa should be examined in regard to mandibular position and morphology. Preliminary work in our laboratory on unipeltatan mouthpart morphology with SEM indicates that this indeed would be a constructive line of research to elucidate the finer points of the radiation of the feeding apparatus of stomatopods.

Nevertheless, the findings here consolidate Schram's hypothesis (Schram, 1969) of the mor- 
phological intermediacy of tyrannophontid stomatopods between the palaeostomatopods and the unipeltatans.

However, Tyrannophontes acanthocercus also exhibits unique characteristics that form no intermediate grade of organization between both these groups. Most notable among these is the most singular structure of the biramous pleopods. A similarity that may prove to be of more than just passing interest is the superficial resemblance of the irregular distal tip of the inner pleopod ramus of $T$. acanthocercus to the petasma on the first pair of pleopods of male unipeltatans. Schram \& Horner (1978) and Factor \& Feldmann (1985) already noted the presence of the annulate ramus of the pleopods. It can now be demonstrated that one branch of the biramous pleopod distinctly varies from the annulate form. Similar pleopods can be seen on Gorgonophontes peleron (e.g., see PE 14394). Biramous pleopods are also indicated in the revised reconstruction of $T$. theridion from the Mazon Creek in 1984 (compare Schram, 1969 and 1984), however, without any explicit mention in the text. In any case, the pleopodal rami of $T$. theridion are described as being unisegmental with a two segmented protopod (Schram, 1969; 1984). The pleopods of unipeltatans are biramous appendages with broad flap-like rami that provide the attachment site of gills. The possession of annulate outer rami on thoracic and abdominal appendages of rapacious hoplocarids might be primitive. Peach (1908) reported the presence of annulate thoracopodal exopods on Bairdops elegans, but their presence was not confirmed by Schram's (1979c) restudy. However, the material may have deteriorated physically since the original description, as was also suggested by Briggs \& Clarkson (1985) when they encountered the same situation regarding the annulate flagella of the antennae.

The sternites of thoracomeres 2 through 5 of $T$. acanthocercus are longer than anything seen in a unipeltatan (Fig. 5). Nevertheless, we can still see a distinct anterior ridge on the inside of the sternite from which arises a posteriorly directed, finger-like apodeme over the entry into the coxa. Unipeltatans also have a well-developed posterior ridge with anteriorly directed apodemes, but these appear to be lacking in $T$, acanthocercus. In addition, unipel- tatans exhibit a telescoping of these segments that is completely lacking in $T$, acanthocercus. Furthermore, the structure of the first thoracomere is at variance with that of the second through fifth. The sternite is much shorter and narrower and appears to possess small coxal holes with less heavily sclerotized ridges that are positioned closer to the medial plane of the sternite than those of the second thoracomere (Fig. 5.1) and those seen on the sternites of unipeltatans. This indicates that the first thoracopod of T. acanthocercus was indeed modified as a maxillipede, but its location is more medial than that seen in unipeltatans.

There are two distinct kinds of body preservation in these fossils, lateral and dorsoventral. Reconciling the differences between these was crucial before a proper reconstruction of the tail fan could be undertaken. The specimens preserved on their sides appear to show a telson with a longitudinal dorsomedian carina, but this interpretation hangs on the assumption that the telson is actually rotated along the anterior-posterior axis and thus exposes an apparent dorsal telson surface. Some specimens are actually preserved in this manner $(P$ 32098). The telson reconstruction of Factor \& Feldmann is consistent with these kinds of specimens. However, other specimens are true lateral preservations (MSNM i 11979, MSNM i 12444, and CM 34455). In these specimens, a longitudinal carina is seen, which extends parallel to the upper surface of the telson. If the telson is regarded as being rotated along the anteroposterior axis, this carina would be incorrectly interpreted as a dorsomedian carina. More posteriorly, however, these carinae join on the upper telson surface. Thus it seems clear that there is not a single median carina, but rather there are paired longitudinal lateral carinae that converge posteriorly upon the median plane of the telson. This interpretation is also compatible with the reconstruction of the telson based on the specimens that are dorsoventrally preserved (MSNM i 11841, MSNM i 12433) (Fig. 4).

There is some variation in telson form apparent on different specimens. For example, the telson of UM 6149 (Pl. III-3) is somewhat more rounded than that of MSNM i 12433 (P1. III-5). That of MSNM i 11841 (Pl. II-5) appears intermediate. The sublateral and submedian carinae of UM 6149 (PI. III-3) 

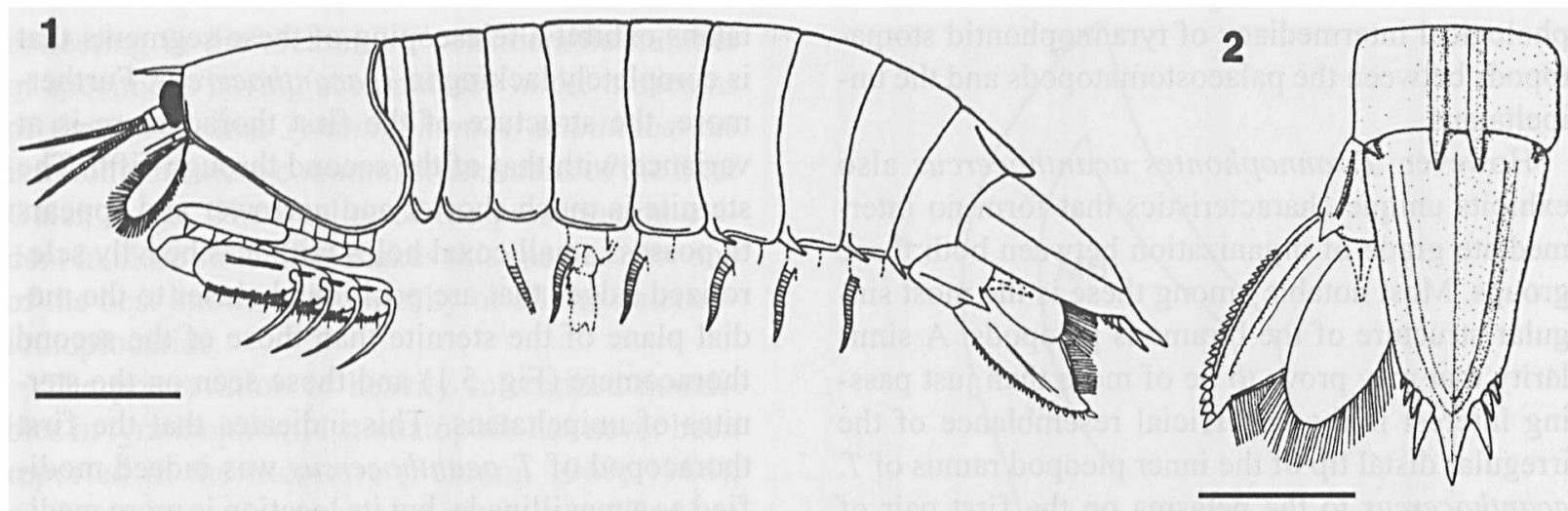

Fig. 4. 1, Lateral reconstruction of Tyrannophontes acanthocercus n. sp., scale bar $=0.95 \mathrm{~cm}$ (dotted lines denote uncertainty); 2 , dorsal tailfan reconstruction of $T$. acanthocercus new species, scale bar $=0.5 \mathrm{~cm}$.

are more closely associated with the dorsomedian carina than those of MSNM i 12433a (PI. III-5). MSNM i 118419 apparently shows only the submedian and dorsomedian carinae. Thus, variation is expressed as differences in telson outline and spatial relationships of the elements of the telson ornament.

Body size is quite variable (see Table I), but the specimens at opposite ends of the spectrum are remarkably isomorphic (e.g., compare UM 6138 and UM 6492). The prominence of the pleural spines on pleomeres three to six also varies (e.g., compare MSNM i 12004 and P 32093). The curvature of the distal tip of the dactyli of the thoracopods can also differ somewhat, even among the subchelae of a single specimen (UM 6022). UM 6271 shows a more remarkable difference with indications of the presence of submedian tergal ridges on both pleomeres 5 and 6 . Furthermore CM 34454 apparently displays a large spine on the thoracopodal carpus, but the pertinent thoracopod is only very faintly preserved. UM 6492 possesses possible scars of such carpal spines, but CM 34457 is the only specimen on which carpal spines appear unambiguously. This latter specimen, however, is of uncertain taxonomic affinity. Finally, specimen MSNM i 11853 shows two dorsal gastric grooves on the carapace extending from both sides of the base of the articulated rostrum posteriorly for approximately one third the length of the carapace and a possible transverse cervical groove. The articulated rostrum on this specimen is large and subrectangular and thus differs somewhat from the usually observed subtriangular rostrum outline. The exact affinity of this specimen also is not clear. UM 6149 also displays possible gastric grooves on the carapace. We record all these variations here, but we believe these do not serve to justify at this time recognition of anything other than a single species.

As mentioned above, Factor \& Feldmann (1985) believed that the Mazon Creek and Bear Gulch tyrannophontids belonged to the same taxon. Schram (1984) revised some morphological details of $T$. theridion Schram, 1969 in his comparison with $G$. peleron. This revision increased the overall similarity of $T$. theridion from the Mazon Creek and the Bear Gulch tyrannophontid. Factor \& Feldmann ascribed observed differences between the Mazon Creek and Bear Gulch tyrannophontids to the vagaries of preservation. Schram's re-examination revised aspects of the initial description of $T$. theridion (Schram, 1969). The propodus of the subchelate thoracopods appeared to be more massive than previously described. In addition, a single row of fine spines was observed to be present on the thoracopodal propodus. The uropod rami were less styliform than originally described and the uropodal protopod seemed to have had a slight posterior extension. A possible diaeresis on the uropodal exopod is only faintly indicated.

How closely does this revised concept of $T$. theridion resemble the morphology of the Bear Gulch tyrannophontids as described by Factor \& Feldmann? In fact, it appears that T. theridion shows only a general resemblance to Factor \& Feldmann's rendering of the Bear Gulch tyrannophontid. The 
Table I. Measurements (cm) of Tyrannophontes acanthocercus $\mathrm{n}$. sp. All measurements are lengths. $\mathrm{Ca}=$ carapace, $\mathrm{Ab}=\mathrm{abdomen}$ (excl. telson), $\mathrm{Te}=$ telson, $\mathrm{Ro}=$ rostrum, $\mathrm{Ur}=$ uropod, exopod margin, $\mathrm{Pr}=$ propodus thoracopod, CeThor $=$ cephalon + thorax.

\begin{tabular}{|c|c|c|c|c|c|c|c|c|}
\hline Specimen & $\mathrm{Ca}_{4}$ & $x^{*}$ & $\mathbf{A b}$ & $\mathrm{Te}$ & Ro & Ur & Pr & CeThor \\
\hline MSNM i 11979 & 0.41 & & 1.18 & 0.42 & $=$ & 0.45 & - & 0.73 \\
\hline MSNM i 12017 & 0.57 & & 1.23 & 0.48 & 0.10 & $=$ & $=$ & 1.04 \\
\hline MSNM i 12002 & 0.53 & & 1.39 & 0.53 & 0.23 & 0.40 & $=$ & 1.14 \\
\hline MSNM i 11841 & 0.73 & & 1.35 & 0.71 & 0.18 & $=$ & $=$ & 1.16 \\
\hline MSNM i 11978 & 0.60 & & 1.43 & 0.55 & 0.16 & 0.40 & 0.32 & 1.75 \\
\hline MSNM i 12145 & $=$ & & 1.92 & 0.75 & * $=$ & $=$ & $=$ & 1.41 \\
\hline MSNM i 12433 & 0.99 & & 2.29 & 1.03 & 0.33 & 0.43 & 0.52 & 1.74 \\
\hline MSNM i 12004 & 0.90 & & 2.52 & 0.89 & 0.42 & $=$ & 0.58 & 1.84 \\
\hline MSNM i 12444 & 1.24 & & 2.62 & 0.88 & 0.22 & $=$ & 0.70 & 2.17 \\
\hline MSNM i 11997 & 0.99 & & 2.76 & 1.13 & 0.26 & 0.69 & 0.49 & 2.04 \\
\hline MSNM i 8785 & 1.35 & & 2.81 & 1.45 & 0.32 & - & $=$ & 2.20 \\
\hline MSNM i 11853 & 0.81 & & $=$ & $=$ & 0.20 & $=$ & $=$ & $=$ \\
\hline CM 34453 & 1.17 & & 3.27 & 1.31 & 0.34 & 1.06 & 0.72 & 2.34 \\
\hline CM 34459 & 1.26 & & 3.62 & 1.57 & 0.34 & 0.92 & $=$ & 2.41 \\
\hline CM 34455 & 1.73 & & 3.65 & 1.56 & $=$ & 1.22 & 0.68 & 2.85 \\
\hline CM 34457 & 1.76 & & $=$ & $=$ & $=$ & $=$ & 0.80 & $=$ \\
\hline CM 34456 & $=$ & & - & 2.42 & $=$ & 1.50 & 1.10 & $=$ \\
\hline CM 34458* & 0.66 & & 1.30 & 1.00 & 0.21 . & $=$ & 0.30 & 1.14 \\
\hline CM 34454 & 0.74 & & 1.88 & 0.78 & 0.19 & $=$ & 0.44 & 1.32 \\
\hline P 32098 & 0.99 & & 2.51 & 0.84 & $=$ & - & $=$ & $=$ \\
\hline P 32093 & - & & 4.49 & 2.05 & = & $=$ & $=$ & $=$ \\
\hline P 32095 & - & & 4.66 & $=$ & - & - & - & $=$ \\
\hline P 32096 & 1.22 & & 3.46 & 1.46 & $=$ & $=$ & $=$ & 2.46 \\
\hline UM 6123 & $=$ & & 4.82 & 2.00 & - & 1.37 & 0.93 & $=$ \\
\hline UM 6267 & $=$ & & $=$ & 2.00 & - & 1.30 & $=$ & - \\
\hline UM 6205 & $=$ & & 4.41 & 1.73 & - & 1.30 & - & - \\
\hline UM 6271 & - & & - & 1.20 & - & 0.96 & - & $=$ \\
\hline UM 6149 & $=$ & & $=$ & 1.04 & $=$ & 0.68 & - & $=$ \\
\hline UM 6138 & 0.74 & & 1.94 & 0.83 & - & 0.60 & 0.44 & 1.35 \\
\hline UM 6492 & 1.73 & & 4.72 & 2.12 & $=$ & - & 0.95 & 3.40 \\
\hline UM 6145 & $=$ & & 2.50 & - & $=$ & - & $=$ & 1.90 \\
\hline
\end{tabular}

Mazon Creek and the Bear Gulch specimens differ in a number of important morphological details including the presence on the Bear Gulch material of: 1) pleural spines on pleomeres three to five, 2) setae on the uropodal endopod and the inner margin of the exopod, 3) spines on the outer margin of the uropodal exopods, 4) two posterior processes on the uropodal protopods, and 5) a median telson spike with one pair of submedian spines and two rows of spines on the propodi of the subchelate thoracopods. The new observations here on the Bear Gulch tyrannophontid only increase the differences between the taxa from the two localities and include: 6) the structure of the pleopods, 7) the submedian ridges on the tergite of the sixth pleomere, and 8) the form and ornament of the telson.
However, it should be noted that the very finegrained micrite sediment of the Bear Gulch Limestone together with the occasional presence of mineralized cuticle on its fossils provides better preservation than the more coarse-grained siderite nodules of the Mazon Creek deposits (Factor \& Feldmann, 1985). Bear Gulch fossils therefore show more preserved morphology, and more clearly so, than the Mazon Creek fossils.

The question then is, can taphonomy of the fossils justify a synonymy of the Bear Gulch and Mazon Creek tyrannophontids? This is what Factor \& Feldmann (1985) did when they concluded that the observed differences between these forms were the result of differences in preservation. However, we believe that the Bear Gulch and Mazon Creek forms 
are different taxa for the following reasons.

Because both faunas are part of a Carboniferous faunal continuum (Schram, 1979b), and consequently exhibit striking taxonomic similarities, we recognize that the geographic and temporal distinctness of the localities in themselves are insufficient reasons for splitting the taxa. Such distinctions can only depend on morphological data. In principle, the morphological data can be interpreted in two ways. Observed differences can be due either to preservational variation, or real anatomical differences. If differences in form are to be viewed as vagaries of preservation, that would $a$ priori exclude characters seen on better preserved forms from meaningful employment as taxonomic descriptors. The alternative explanation is that discrete observed differences in anatomy have potential taxonomic value. Therefore, detailed differences that are observed between the Bear Gulch and Mazon Creek tyrannophontids could then be regarded as sufficient for separating them as distinct taxa. Under the terms of the a priori assumption that anatomical variation results from differences in preservation, the possibility of taxonomic distinctness becomes impossible to support. Under the terms of assuming that observed differences have potential meaning, the possibility of taxonomic distinctness becomes a viable option to be tested by evaluation of all the evidence.

The aeschronectids from the Mazon Creek prove that such delicate structures as setae and tufted gills can be preserved. This indicates that there is no absolute taphonomic boundary that could have prevented the preservation of details on the Mazon Creek fossils. Until further analysis yields new data on the preservational quality of both localities (e.g., by comparing the preservation of species present at both localities), there is no compelling reason to assume that preservational differences are the exclusive cause of the observed differences.

Tyrannophontes acanthocercus also shows substantial similarity to Gorgonophontes peleron. The overall similarity of the tail fan especially suggests close comparison. Both species have a telson with a subrectangular base tapering off to a median spike; they share the lobate nature of the uropod rami and the setose margins of the endopod and inner part of the exopod. A larger process of the uropodal protopod seems to be a basal prolongation projecting underneath the endopod while a smaller process projects over the exopod (PE 14319; see fig. 3D in Schram, 1984). The propodi of the subchelate thoracopods bear two parallel rows of unequally sized spines and the propodus and carpus appear equally massive (although differing in size). The uropodal endopod of G. peleron is more rounded and lobate than depicted in the reconstruction (Schram, 1984), based on re-examination of material available from the Field $\mathrm{Mu}$ seum. It differs from that of $T$. acanthocercus by terminating in a narrow distal tip (PE 19259, PE 14344; see fig. 4C in Schram, 1984). In addition, the supposed diaeresis on the uropodal exopod of G. peleron may be absent, since it appears now that, rather than being a genuine transverse groove, the presumed diaeresis only appears as a discontinuity in the preservation of mineralized cuticle (PE 14344). An examination of Schram's original camera lucida drawings of G. peleron adds support to the argument against the presence of a diaeresis. The uropodal endopod appears to be incorrectly interpreted as the proximal inner part of the uropodal exopod, thus suggesting the transition from endopod to exopod as a diaeresis. The two telson carinae of G. peleron may define an elevated area on the telson in the way of the Bear Gulch taxon (PE 14259, PE 14341), and the sixth pleomere shows two submedian, dorsal ridges which might extend beyond the posterior margin of the tergite (PE 14319) along with indications of submedian telson spines (PE 19251, PE 14319). The pleural ridges of the pleomeres of $G$. peleron are equally prominent as in the Bear Gulch specimens, PE 14259, PE 19259, and specimen PE 14394 shows robust, heavily sclerotized, pleopodal rami accompanied by proximal remnants of a slender annulate ramus positioned underneath the anteriormost pleomeres.

The main differences are the length of the dactylus of the subchelate thoracopods, the segmentation of the thoracopods, the form of the abdominal pleurae, the presence or absence of pleural spines, the ornaments of the uropodal rami (serration and moveable spines on the outer margin of the uropodal exopod of the Bear Gulch tyrannophontid), the exact carination and spination of the telson and the 
size of the lateral carapace wings. Cladistic analysis (see below) indicates that these differences are sufficient to retain the Bear Gulch tyrannophontid within the genus Tyrannophontes. However, a restudy of all the original material of G. peleron would be recommended. For example, it would be useful to look at the exact spination pattern on the thoracopodal propodi and to determine whether the subchelae of the thoracopods are larger relative to body length than those of $T$. theridion and $T$, acanthocercus.

Order Palaeostomatopoda Brooks, 1962

Family Perimecturidae Peach, 1908

Genus Bairdops Schram, 1979

Type species. - Perimecturus elegans (Peach, 1908), from the Viséan of Scotland (Glencartholm fauna).

Bairdops beargulchensis Schram \& Horner, 1978 (Figs. 5.2, 6 \& Pls. IV, V)

Synonymy. - Bairdops beargulchensis Schram \& Horner, 1978, in part, pl. 1, fig. 5 .

Tyrannophontes theridion Schram, 1969 sensu Factor \& Feldmann, 1985, in part, fig. 6.2 .

Material examined. - P 32092, 32094; UM 6194, 6217 (holotype).

Occurrence. - UM 6194, 6217 come from locality MV 7106; P 32092, 32094 are from T14N, R22E.

Diagnosis. - Palaeostomatopod with carapace extending dorsally to anterior margin of eighth thoracomere and laterally to anterior margin of first pleomere. Four pairs of unarmed subchelate thoracopods. Posteriorly directed processes projecting from dorsal, posterior margins of fifth and sixth pleomeres. Uropodal protopods with posterior directed dorsal process.

Description. - The cephalic appendages are for the most part not preserved. Specimens P 32094, UM 6217 and possibly UM 6194 show remnants of at least one elongated peduncular segment of the second antennae (Pl. IV-1). These specimens also preserve parts of an antennal scaphocerite. UM 6194 displays an antennular peduncle consisting of three rather broad segments. Specimen $P 32094$ possesses a large rounded eye and reveals a large, massive mandibular body. The distorted carapace, however, prevents an accurate estimation of the position of the mandible along the length of the cephalothorax.

The carapace is large, elongated and subrectangular in lateral view and covers almost the entire thorax. In lateral aspect, the posterior carapace margin is slightly sigmoid with a convex ventrolateral corner and a slightly concave posterodorsal region (UM 6217) (PI. IV-2). Both in lateral and dorsal aspect, the anterior carapace margin is slightly concave (UM 6217, UM 6194). Dorsally it extends approximately to the anterior margin of the eighth thoracomere and laterally to about the anterolateral margin of the first pleomere (Pls. IV-2, V4). The carapace has a marginal furrow (UM 6217, $P$ 32094). A large articulated rostrum, about a third as long as the carapace, appears on UM 6217 and UM 6194. In lateral view it appears spatulate.

All the thoracomeres are smaller in length than the pleomeres, and there is a large size difference between the first pleomere and the eighth thoracomere. A modest degree of tagmatization of the thorax is observable. The posteriormost thoracomeres (probably the sixth to eighth) are somewhat larger than the anterior thoracomeres (P 32092) (PI. $\mathrm{V}-3)$. The anterior thoracomeres have narrow sternites (P 32092, UM 6194) with rounded coxal holes (P 32092) (Fig. 5.2 and Pl. V-2, 3). UM 6194 and $P$ 32092 possess laterally distorted sternites (to the right and to the left, respectively) that are surrounded by well-sclerotized apodemes. Remnants of thoracopod segments are located lateral to the sternites.

The exact structure of the thoracopods is vague, but the nature of their folding on UM 6217 and $P$ 32094 suggests they are subchelate (Pl. IV-1, 2). At least four pairs are preserved (UM 6217), but it is unclear to which thoracomeres they belong. There seems to be a moderately sized coxa and a long basis, followed by short, subequal ischiomerus and carpus and a longer, unarmed propodus and dactylus. UM 6217 shows some remains of a possible eighth thoracopod underneath the eighth thoracomere.

The pleomeres decrease both in height and width 

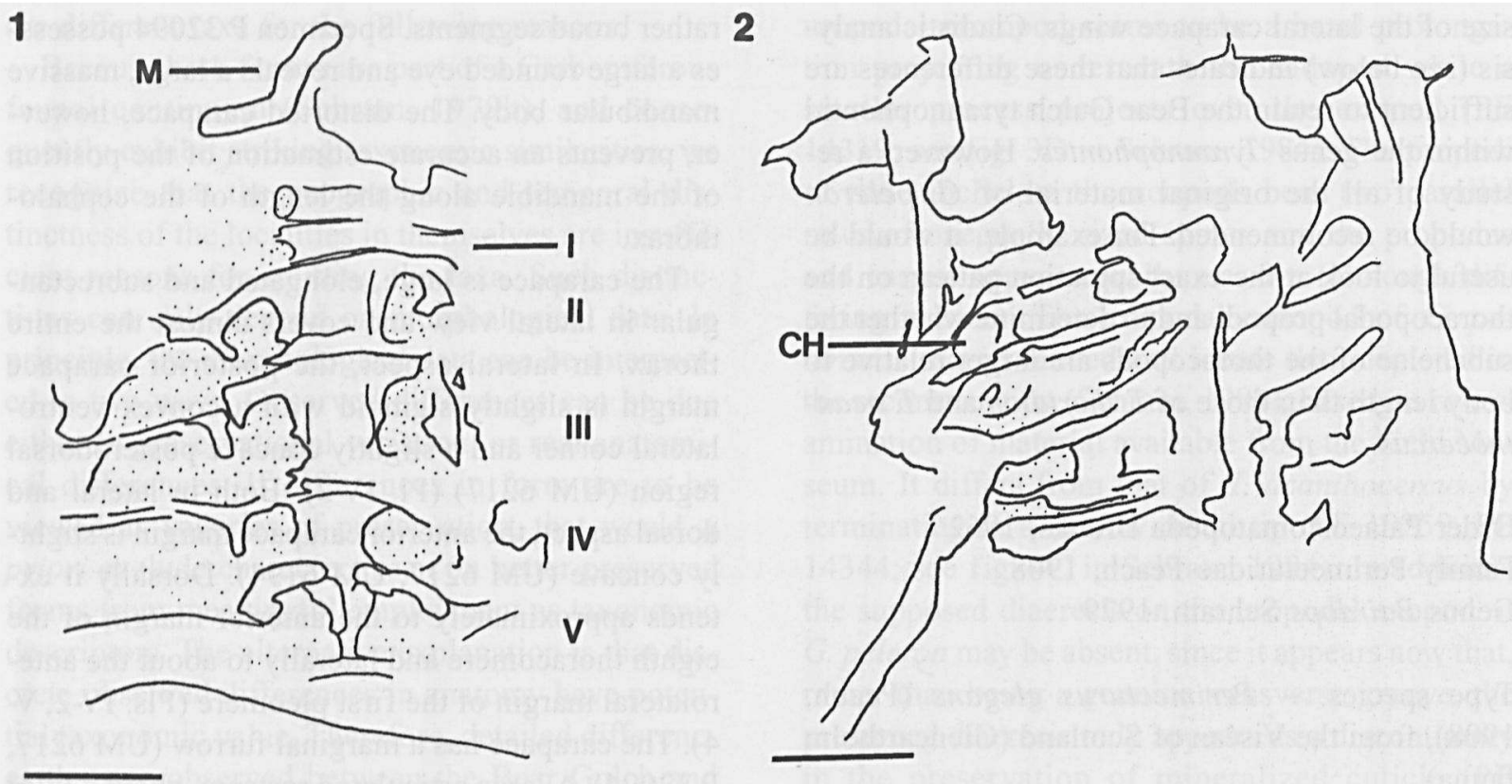

Fig. 5. Camera lucida drawings of the anterior thoracal sternites: 1 , Tyrannophontes acanthocercus $\mathrm{n}$. sp., Roman numerals denote the thorax segments, scale bar $=0.12 \mathrm{~cm} ; 2$, Bairdops beargulchensis Schram \& Horner, 1978 , scale bar $=0.25 \mathrm{~cm} . \mathrm{CH}=$ coxal hole, $\mathrm{M}=$ mandible.

posteriorly (UM 6217, P 32092). The pleomeral pleurae have relatively straight ventral margins, running parallel to the trunk axis, with rounded corners. They have a moderate marginal furrow and ridge. $\mathrm{P} 32094$ seems to have a posterior, dorsal, posteriorly directed process on the tergites of pleomeres five and six (Pl. IV-1). This may be indicative of the presence of one or two submedian tergal ridges on these pleomeres with processes extending beyond the anterior margin of the sixth pleomere or telson margin, respectively. P 32092 only very unclearly shows two submedian tergal ridges on pleomere six. The structure of the pleopods is unknown. UM 6217 shows a robust heavily sclerotized structure underneath the boundary between the fifth and sixth pleomere, which may represent part of a pleopod. The pleopodal coxal holes are large (UM 6194, P 32092).

The tail fan is rather delicate: the body of the telson is not particularly massive nor robust. The subrectangular telson base tapers to a long median telson spike that is flanked by two slender lobes or spines (UM 6194) (Pl. V-1). A median telson crest is defined by a median carina and two posteriorly converging lateral carinae (UM 6194). The uropo- dal protopods appear to have a posteriorly directed process projecting over the rami (UM 6194). The uropodal exopod is slender and blade-like. The well-sclerotized outer part attaches to a narrow, more membranous inner portion. The exopod is approximately as long as the distance from the anterior telson base to the submedian spines or furca. The endopods appear as small membranous flaps.

Fig. 6 shows a schematic reconstruction of Bairdops beargulchensis. Table II offers some representative measurements.

Remarks. - While Bairdops beargulchensis is now more clearly understood in terms of its defining characters, it also becomes one of the rarer crustacean elements in the Bear Gulch fauna. However, its affinities to the Scottish species, $B$. elegans, and the other palaeostomatopods is apparent.

As discussed above, Factor \& Feldmann (1985) concluded that Bairdops beargulchensis is the junior synonym of Tyrannophontes theridion. Unfortunately, they did not explicitly elaborate on the reasons underlying their conclusion. However, our restudy of the fossils originally used for the description of $B$. beargulchensis sheds light on how 

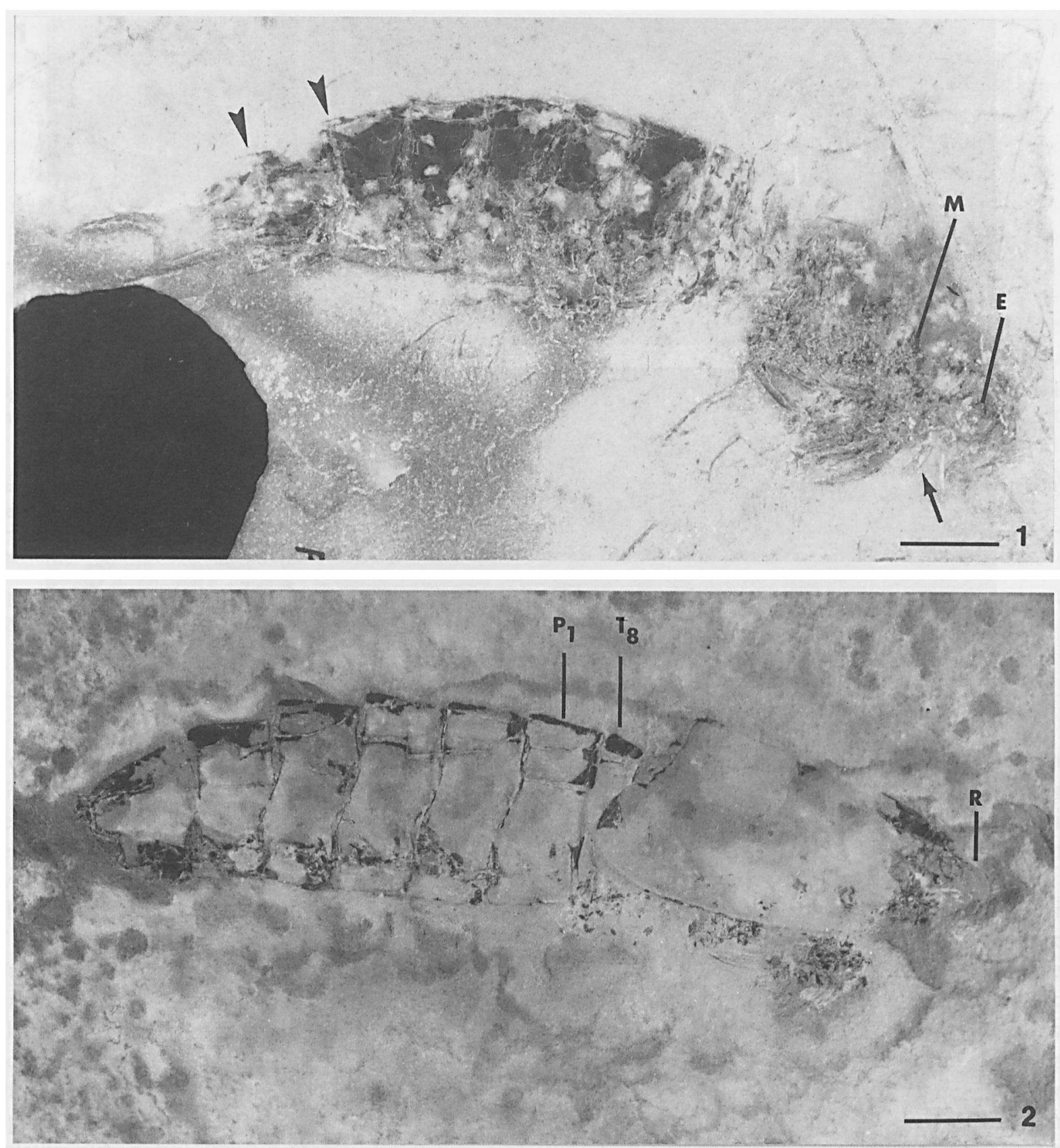

Pl. IV. Bairdops beargulchensis Schram \& Horner, 1978: 1, P 32094, lateral view, arrowheads indicating dorsal pleomere processess and arrow indicating antennal peduncular segment, scale bar $=0.55 \mathrm{~cm} ; 2$, holotype, UM 6217 , lateral view, scale bar $=0.97 \mathrm{~cm}$. $E=$ eye, $\mathrm{M}=$ mandible, $\mathrm{P}_{1}=$ pleomere $1, \mathrm{R}=$ rostrum, $\mathrm{T}_{8}=$ thoracomere 8 .

Factor \& Feldmann could have concluded that $B$. beargulchensis and $T$. theridion were in the same taxon. We now clearly see that Schram \& Horner confused specimens of two distinct taxa in their description of $B$. beargulchensis. Consequently,
Schram \& Horner (1978, plate 1, fig. 3) depict the Bear Gulch tyrannophontid instead of true $B$. beargulchensis, and Factor \& Feldmann (1985, fig. 6.2) depict $B$. beargulchensis instead of T. theridion. Thus $B$. beargulchensis in 1978 was a compila- 

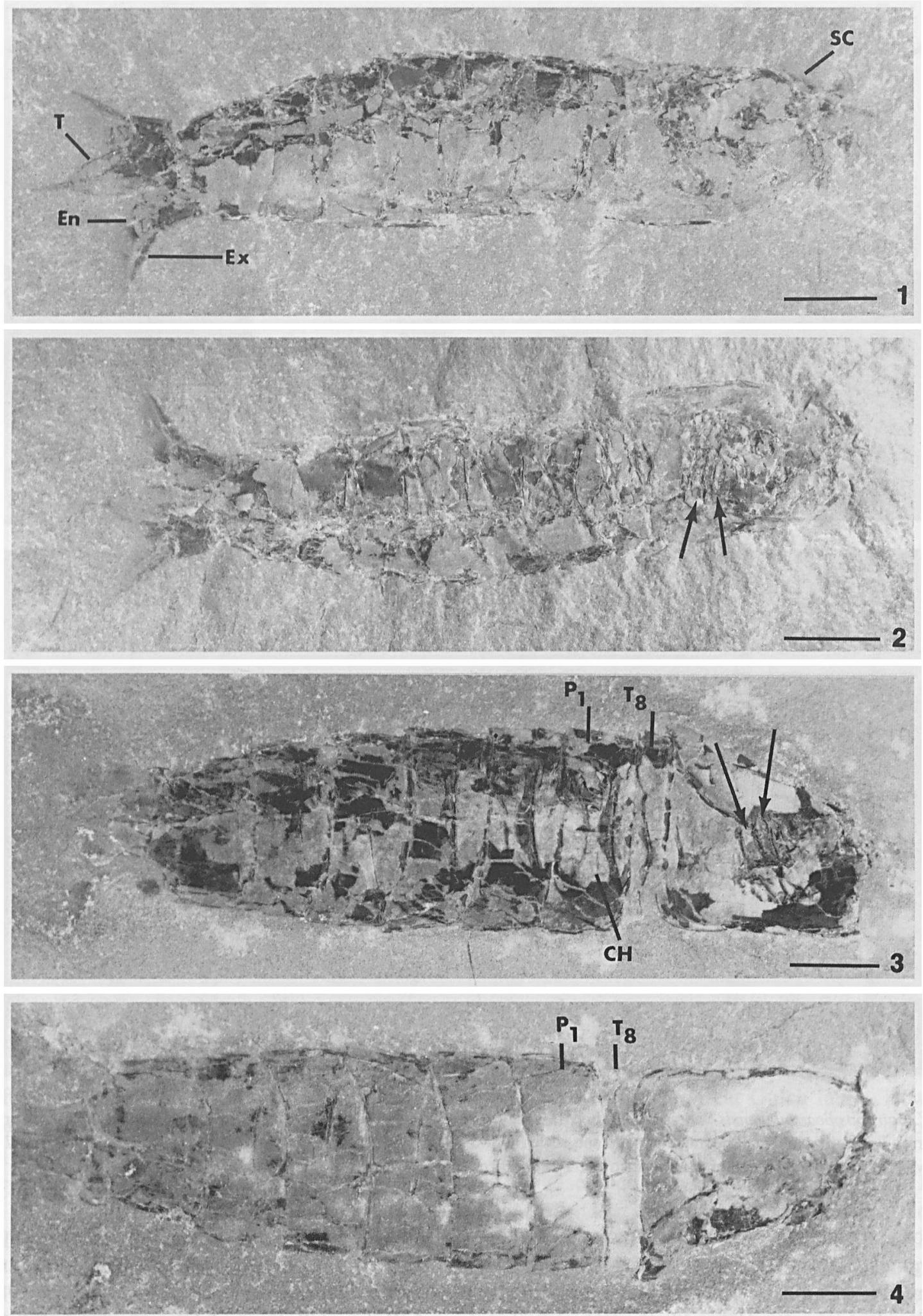


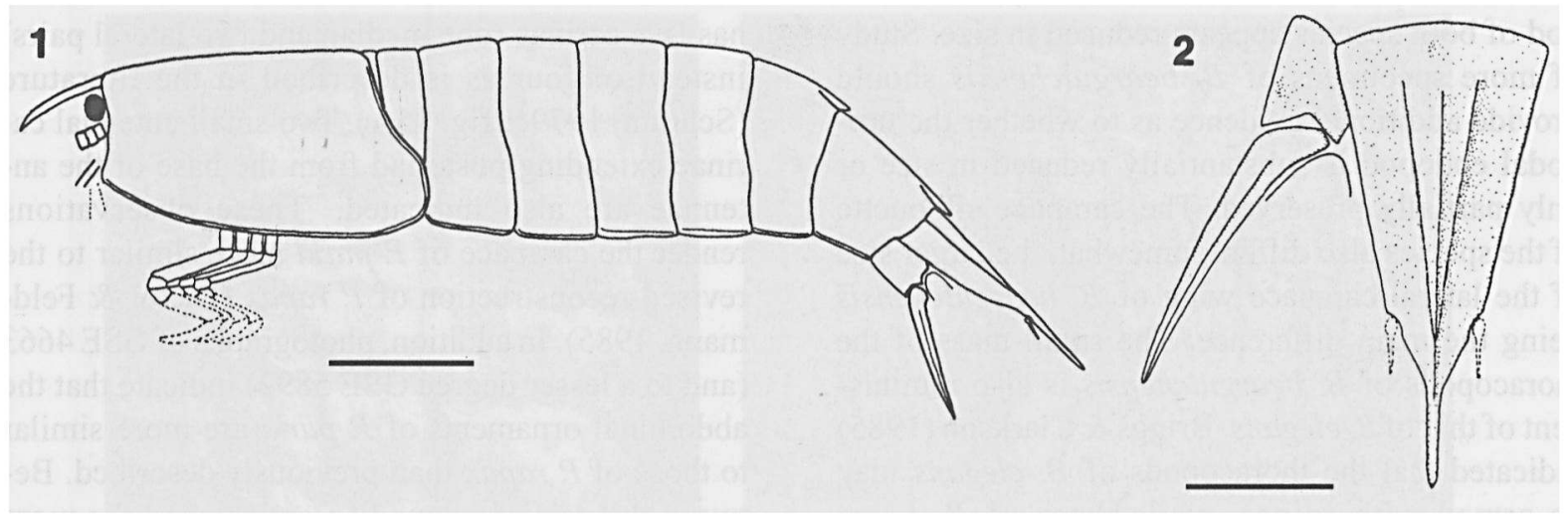

Fig. 6. 1, Lateral reconstruction of Bairdops beargulchensis Schram \& Horner, 1978, scale bar $=1.5 \mathrm{~cm}$ (dotted lines denote uncertainty); 2, dorsal tailfan reconstruction of B. beargulchensis Schram \& Horner, 1978, scale bar $=0.47 \mathrm{~cm}$.

Table II. Measurements (cm) of Bairdops beargulchensis. All measurements are lengths. $\mathrm{Ca}=$ carapace, $\mathrm{Ab}=\mathrm{abdomen}(\mathrm{excl}$. telson), $\mathrm{Te}=$ telson, $\mathrm{Ro}=$ rostrum, $\mathrm{Ur}=$ uropod, exopod margin, $\mathrm{Pr}=$ propodus thoracopod, CeThor $=$ cephalon + thorax.

\begin{tabular}{|c|c|c|c|c|c|c|c|}
\hline specimen - & $\mathrm{Ca}$ & $\mathrm{Ab}$ & $\mathrm{Te}$ & Ro & Ur & $\mathrm{Pr}$ & CeThor \\
\hline UM 6194 & 1.92 & 3.80 & 1.40 & 0.55 & - & - & 2.20 \\
\hline UM 6217 & 2.60 & 5.30 & - & 1.00 & - & - & 3.30 \\
\hline P 32092 & 1.70 & 3.57 & 1.40 & - & - & - & 1.98 \\
\hline P 32094 & 1.75 & 3.19 & 0.80 & - & - & - & 2.01 \\
\hline
\end{tabular}

tion of characters to be found on both the Bear Gulch tyrannophontid and palaeostomatopod. As a result, Factor \& Feldmann, in noting that characters of $B$. beargulchensis were present on fossils with a tyrannophontid morphology, concluded that all the B. beargulchensis were Tyrannophontes.

Despite this confusion, we confirm that in fact there are some specimens attributable to $B$. beargulchensis that are genuine palaeostomatopods characterized by the presence of a large carapace covering almost all of the thorax. The telsons of the Bear Gulch tyrannophontids and palaeostomatopods show a superficial resemblance, but their relative size, form, and ornament are sufficiently distinct to justify separate status. In addition, $B$. beargulchensis is easily distinguished from the tyrannophontid by the large difference in size between the first pleomere and the eighth thoraco- mere and the lesser degree of thoracic tagmatization characteristic of palaeostomatopods. The overall mass of the thoracopods of $B$. beargulchensis is also modest when compared with those of tyrannophontid stomatopods.

The overall morphology of $B$. beargulchensis is very similar to that of $B$. elegans, especially in regard to the structure of the tail fan. Both species have slender telsons with a long median spike flanked by spines or caudal furca. $B$. elegans also possesses a median crest on the telson. Although not mentioned in its original description (Schram, $1979 \mathrm{c})$ this crest is defined by three carinae: one median and two submedian. This closely resembles the situation in $B$. beargulchensis. Furthermore, both species share a narrow, blade-like uropodal exopod with a more heavily sclerotized outer part and a more membranous inner part. The endo-

\section{$\leftarrow$}

Pl. V. Bairdops beargulchensis Schram \& Horner, 1978: 1, UM 6194, dorsal view, scale bar $=0.8 \mathrm{~cm} ; 2$, UM 6194, ventral view (counterpart of V-1), arrows indicating anterior thorax sternitës, scale bar $=1.0 \mathrm{~cm} ; 3, \mathrm{P} 32092$, ventral view abdomen and carapace, dorsal view telson, arrows indicating anterior thorax sternites, scale bar $=0.7 \mathrm{~cm} ; 4, \mathrm{P} 32092$, dorsal view abdomen and carapace, ventral view telson (part of $\mathrm{V}-3$ ), scale bar $=0.65 \mathrm{~cm} . \mathrm{CH}=$ coxal hole of pleopod, En = endopod of uropod, Ex = exopod of uropod, $\mathrm{P}_{1}=$ pleomere $1, \mathrm{SC}=$ scaphocerite, $\mathrm{T}=$ telson, $\mathrm{T}_{8}=$ thoracomere 8 . 
pod of both species appears reduced in size. Study of more specimens of $B$. beargulchensis should provide additional evidence as to whether the uropodal endopod is substantially reduced in size or only partially preserved. The carapace silhouette of the species also differs somewhat, the larger size of the lateral carapace wing of $B$. beargulchensis being the main difference. The small mass of the thoracopods of $B$. beargulchensis is also reminiscent of that of $B$. elegans. Briggs \& Clarkson (1985) indicated that the thoracopods of $B$, elegans may be armed with spines, while those of $B$. beargulchensis appear unarmed. Currently, the morphological differences between the species are fairly limited. These include (excluding cephalic appendages exclusively observed on $B$. beargulchensis and pleopods on $B$. elegans) the outline of the carapace, the presence of thoracopodal propodus spines on $B$. elegans, the possible presence of submedian tergite ridges on pleomeres five and six that form posteriorly directed processes on $B$. beargulchen$s i s$, the presence of a genuine process on the uropodal protopod on $B$. beargulchensis, and possibly the nature of the uropodal endopods.

\section{Genus Perimecturus Peach, 1908 (Pl. VI)}

Remarks. - Some preliminary observations on some fossils of Perimecturus rapax from the Bear Gulch Limestone in comparison with photographs of $P$ parki from the Glencartholm fauna of Scotland reveal some potentially interesting new characters that invite a detailed restudy of all the pertinent fossils in this genus.

CM 33934 (P. rapax) shows that the uropodal protopods possess two posteriorly directed processes as observed by Schram \& Horner (1978) and Factor \& Feldmann (1985). The large process closest to the telson is a basal prolongation while the smaller process is a dorsal projection over the exopod. This clearly resembles the situation in $T$ a acanthocercus and probably G. peleron.

Detailed analysis of photographs of $P$ park $i$ indicate that the number of purported differences with $P$ rapax probably can be decreased considerably. These differences are centered on the details of carapace, abdominal and tail fan ornaments. The photograph of GSE 5896 shows that the carapace has five carinae (one median and two lateral pairs) instead of four as is described in the literature (Schram, 1979c: fig. 15A). Two small antennal carinae extending posteriad from the base of the antennae are also indicated. These observations render the carapace of $P$. parki more similar to the revised reconstruction of $P$ rapax (Factor \& Feldmann, 1985). In addition, photographs of GSE 4663 (and to a lesser degree GSE 5892) indicate that the abdominal ornaments of $P$ parki are more similar to those of $P$. rapax than previously described. Between the pair of submedian carinae and the more laterally located pair of carinae appears to be a row of nodes similar to those observed on P. rapax (Factor \& Feldmann, 1985) (PI. VI-1). A final uniting character of the perimecturids apparently is the presence of spines, possibly movable, on the distal part of the outer margin of the uropodal exopod, now also demonstrated to be present on $P$ p parki (Pl. VI-2).

\section{Discussion}

\section{Body form inference}

It seems reasonable to use the frequency of animals positioned on either their ventral or lateral sides as an indicator of body form (dorsoventrally or laterally flattened or cylindrical). However, there are additional factors influencing the attitude of the body to the sediment surface. Among these post mortem factors may be flexion of the abdomen and the telson and unfolding of the thoracopods. These changes may reposition the animal from its normal life mode. Peach (1908) argued for post mortem changes in body form to explain the observation that many fossil crustaceans are preserved on their lateral sides. Experimental, taphonomic data also point to the repositioning of the body after death in shrimps (Briggs \& Kear, 1994). In stomatopods, the decay of the propodal muscles releases the click-joint mechanism of the thoracopods resulting in the unfolding of the propodus and merus. This can lead to the repositioning of the animal on its side (Hof \& Briggs, in press).

A potentially important source for arthropod fossils may result from the molting process. Shed ex- 

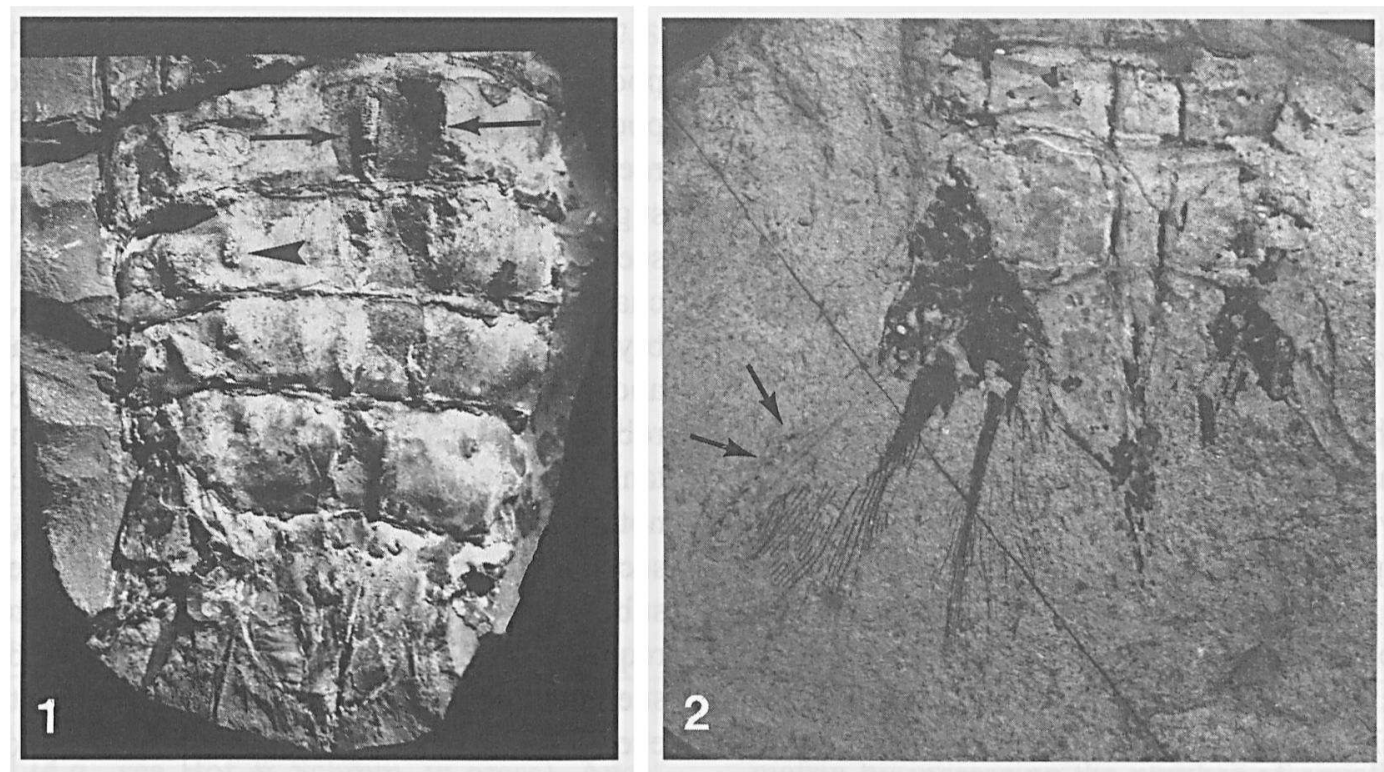

Pl. VI. Perimecturus parki (Peach, 1882) from the Glencartholm fauna of Scotland: 1, GSE 4663, dorsal view of abdominal ornaments with submedian carinae (arrows) and intermediate and lateral carinae (arrowhead); 2, GSE 5892, dorsal view of posterior abdomen and tailfan, arrows indicating spines on the distal part of the uropodal exopod.

uviae may be indistinguishable as fossils from actual animals, especially if they remain articulated. Molts of decapod crustaceans and unipeltatan stomatopods characteristically exhibit a separated cephalothorax and abdomen (Mikulic, 1990; Rea$\mathrm{ka}, 1975$ ). Such separation is observed in the fossil record as well (MSNM i 11978, MSNM i 11979), (Mikulic, 1990; Schram, 1979c: fig. 16a). Such disarticulation can have an effect on the positioning of the animal relative to the sediment, but it is very difficult to distinguish molts from similarly oriented actual animals. In addition to these morphology-based explanations, some environmental factors, such as catastrophic burial, may cause preservation of the body in an "unnatural" attitude. Thus, the frequency of ventrally or laterally preserved animals is not necessarily a straightforward indicator of body form. Simple observation of body form may also be misleading. This is certainly relevant in interpreting the Bear Gulch hoplocarids (e.g., see Schram, 1979c: fig. 16a, for an unusual lateral preservation of Perimecturus parki).

\section{Taphonomic considerations}

Until recently, the excellent preservation of the Bear Gulch fossils was considered largely the re- sult of high sedimentation rates combined with low oxygen levels at the sediment-water interface (Williams, 1983). Recent studies of taphonomy, however, indicate a less direct role for anoxia as a general preservation-promoting factor (Allison, 1988a; $1988 \mathrm{~b}$ ). These studies reveal that anoxic conditions do not substantially enhance preservation potential of soft tissue. Mineral diagenesis of organic material exerts a more direct control on preservation. Anoxic conditions may then enhance preservation indirectly by facilitating the formation of diagenetic mineral precipitates. In addition, the fact that the salinity levels at the three major Carboniferous near-shore marine communities (Bear Gulch, Glencartholm and Essex fauna of the Mazon Creek) were probably lower than normal marine levels suggests a role for lowered salinity as an abiotic factor facilitating exceptional preservation (Briggs \& Clarkson, 1989).

In a number of instances apparent structural features on the fossils probably represent masked taphonomic artefacts. Among the $B$. beargulchensis fossils, UM 6217 (Pl. IV-2) and P 32092 (P1. V4) apparently show cuticular structures that might be interpreted as lateral and dorsomedian carinae. However, their relative position varies from specimen to specimen, and they can be inconsistent in 
form even on a single specimen. P 32092 for example, shows median ridges on the first three pleomere tergites that are not in line with each other. Similarly looking structures are present in more lateral positions as well but they are inconsistently distributed over the tergites.

\section{Notes on thoracopod structure and function}

We might ask, what does the structure of the anterior subchelate thoracopods of archaeostomatopods reveal about their function? The relationship and the proportions of the thoracopodal segments are akin to those seen on the third to fifth pairs of thoracopods of unipeltatan stomatopods. This includes a relatively long slender basis and a relatively short ischiomerus (merus) and carpus (Kunze, 1981). The similarity between the thoracopods of tyrannophontids and pair three to five in unipeltatans is not a strict point for point correspondence, but it may warrant a functional comparison relative to the specialized second pair of thoracopods present in unipeltatans.

The unipeltatan second pair of thoracopods are extremely specialized in both form and function. The whole limb is large relative to the other thoracopods. The ischiomerus is well developed and connects to a short carpus. A large subchela is formed by a large propodus and dactylus, which may or may not possess spines. The specialized anatomy of the unipeltatan second thoracopods facilitates the very rapid prey capture strike characteristic of these stomatopods (Burrows, 1969). The ischiomerus and the carpus are connected by a specialized articulating joint. This joint is operated through a set of muscles that are accommodated in the large ischiomerus. The specialized conformation of the muscles and associated exoskeletal parts is termed a click-joint mechanism. This mechanism allows the build up of tension in the muscles and tendons before the actual strike. The stored energy is suddenly released when the mechanism is unlocked. As a result the carpus and subchela swing forward. This organization and the associated ability for ballistic movement of the subchela is not reported for thoracopods three to five. The latter limbs are employed in manipulating food after capture and tearing it apart (Kunze, 1981).
Traditionally, the battery of subchelate thoracopods of archaeostomatopods and palaeostomatopods are compared to the third through fifth thoracopods of unipeltatans. Such comparisons suggested similar function. However, the situation seems more complex than that. The limbs of archaeostomatopods and palaeostomatopods probably lack the click-joint mechanism as outlined above. Nevertheless, these limbs are clearly more robust than the third through fifth of the unipeltatans. The evolution of the unipeltatans then may not have involved so much the enlargement of the second thoracopod as the reduction of the other subchelate limbs. Obviously this is a matter that requires further investigation that cannot be pursued here. We could then venture to suggest, however, based on the structure of the thoracopods, that archaeostomatopods, and possibly the palaeostomatopods as well, could have functioned as opportunistic scavengers, specialized in the handling of dead food, while the later unipeltatans became specialized for the active capture of prey using their ballistic second thoracopods.

\section{Phylogenetic analysis}

Schram (1986) performed the first cladistic analysis of all the crustacean higher taxa. His effort solved some of the problems inherent in the less rigorously defined and therefore more "subjective" classical method of evolutionary systematics. In his analysis, fossil and extant taxa were treated equally to cover as much as possible of the evolutionary history of crustaceans. Inclusion of fossil forms proved to be vital for a proper and complete understanding of the phylogenetic history of the group. Schram \& Hof (in press) have essentially built on that initial effort and achieved much the same results.

It is particularly important to include fossil forms in any analysis of hoplocarid relationships. Two of the three currently recognized orders and the suborder Archaeostomatopodea are exclusively Late Paleozoic. In addition, phylogenetically important unipeltatan forms such as Sculda and Pseudoscul$d a$ are also extinct and new fossil species of unipeltatan stomatopods are continuously being de- 
Table III. Data matrix of the phylogenetic analysis of Fig. 7. See appendix for annotated list of characters.

\begin{tabular}{|c|c|c|c|c|c|c|c|c|c|c|c|c|c|c|c|c|}
\hline x & $\times 1$ & $\begin{array}{l}: \\
\vdots \\
x\end{array}$ & 3 & 4 & 5 & 6 & 7 & 8 & 9 & $\begin{array}{l}1 \\
0\end{array}$ & $\begin{array}{l}1 \\
1\end{array}$ & $\begin{array}{l}1 \\
2\end{array}$ & $\begin{array}{l}1 \\
3\end{array}$ & $\begin{array}{l}1 \\
4\end{array}$ & $\begin{array}{l}1 \\
5\end{array}$ & $\begin{array}{l}1 \\
6\end{array}$ \\
\hline euphausian & 0 & 0 & 0 & 0 & $?$ & 0 & 0 & 3 & 0 & 0 & 0 & 0 & 0 & 0 & 1 & 2 \\
\hline K. richardsoni & 0 & 0 & 0 & $\mathbf{0}$ & $?$ & 0 & 0 & 3 & 0 & 0 & 0 & 0 & 0 & $?$ & 1 & 2 \\
\hline A. vermiformis & 1 & 0 & 0 & 1 & 0 & 1 & 0 & 0 & 0 & $?$ & 0 & 0 & 0 & $?$ & 1 & $?$ \\
\hline B. elegans & $\mathbf{0}$ & 0 & $\mathbf{0}$ & 1 & 0 & 1 & 0 & 0 & 0 & 0 & 1 & 0 & 1 & $?$ & 0 & 0 \\
\hline B. beargulchensis & $\mathbf{0}$ & $\mathbf{0}$ & $\mathbf{0}$ & 1 & 0 & 0 & 0 & 0 & 0 & $?$ & 1 & 0 & $?$ & $?$ & 0 & 0 \\
\hline P. rapax & 0 & 0 & $\mathbf{0}$ & 1 & $?$ & $?$ & $?$ & $?$ & 2 & $?$ & 1 & 1. & 1 & 1 & 0 & 0 \\
\hline P. parki & 0 & 0 & 0 & 1 & 0 & 0 & 0 & 0 & 0 & $?$ & 1 & 1 & 1 & 1 & 0 & 0 \\
\hline G. peleron & 2 & 0 & 0 & 1 & 0 & 2 & 0 & 1 & 0 & 1 & 0 & 0 & 0 & $?$ & 0 & 1 \\
\hline T. theridion & 2 & 0 & 0 & 1 & 0 & 2 & 0 & 0 & 1 & $?$ & 0 & 0 & 0 & $?$ & 0 & 1 \\
\hline T. acanthocercus & 2 & 0 & 0 & 1 & 0 & 2 & 0 & 0 & 1 & 1 & 0 & 1 & 0 & 1 & 0 & 1 \\
\hline Ps. laevis & 2 & 1 & 1 & 1 & 1 & $?$ & $\mathbf{0}$ & $?$ & 0 & $?$ & 1 & 1 & 0 & 1 & 0 & 2 \\
\hline S. pennata & 2 & 1 & 1 & 1 & $?$ & $?$ & $?$ & $?$ & 0 & 0 & 0 & 1 & 0 & 1 & 1. & 2 \\
\hline unipeltatans & 2 & 1 & 1 & 1 & 1 & $1 / 3$ & $0 / 1$ & 2 & $0 / 3$ & 0 & $0 / 2$ & 1 & 0 & 1 & $0 / 1$ & 2 \\
\hline
\end{tabular}

scribed (e.g., see Hof \& Schram, in press). Apart from significantly contributing to the numbers of taxa available for study, the fossil forms also contribute unique morphological data to any phylogenetic analysis.

We undertook a cladistic analysis that specifically focused on the Paleozoic groups. Some 16 characters in 13 taxa (Table III) were analysed using PAUP with the Branch-and-Bound option. All characters were treated as unordered and equally weighted. Multiple character states were treated as polymorphisms employing ACCTRAN. The annotated list of characters and character states is given in the appendix. Our analysis yielded three mostparsimonious trees with a length of 31 steps, a CI of 0.839 , a RI of 0.865 and a RC of 0.725 . Fig. 7 shows the strict consensus tree with unambiguous character state changes plotted along the branches.

We wanted to elucidate the relationships of the palaeo- and archaeostomatopods. Therefore all described species were included in the analysis with two exceptions. The palaeostomatopod $\mathrm{Ar}$ chaeocaris graffhami is known only from four specimens, the preservation of which allowed only the partial reconstruction of the thoracopods and the tail fan (Schram, 1979a). Consequently, approximately 60 percent of the characters we scored were "unknown" for this species. Inclusion of taxa with" a high proportion of missing characters can lead to obfuscation of phylogenetic signal present in a data matrix by increasing the number of equally mostparsimonious trees (Wilkinson, 1995). However, exclusion of taxa from an analysis can also result in altered relationships of the remaining taxa. Wilkinson devised some rules for "safe taxonomic reduction" that allow the detection of taxa that do not contribute unique character combinations to the data matrix. Such taxa can safely be excluded from the analysis because they do not contribute unique information to the reconstruction of phylogenetic relationships. Following these rules, we decided that $A$. graffhami was the cladistic equivalent of $A$. vermiformis and could therefore be safely excluded. The archaeostomatopod Tyrannophontes fraiponti similarly is only incompletely known and does not contribute essential phylogenetic data to the analysis. Finally, a generalized euphausian (Eumalacostraca) was used as an out-group and the five superfamilies of extant stomatopods are lumped under "unipeltatans" in the analysis. Final$1 \mathrm{y}$, Kallidecthes richardsoni was included because it is one of the most completely described aeschronectids.

The basic topology of the strict consensus tree resembles that of Schram's order-level analysis of hoplocarid relationships (Schram, 1986: fig. 43-4). The first split is between the rapacious forms with subchelate thoracopods and the forms with achelate thoracopods. The large clade of rapacious forms is characterized by the possession of a tagmatized thorax with subchelate thoracopods on the 


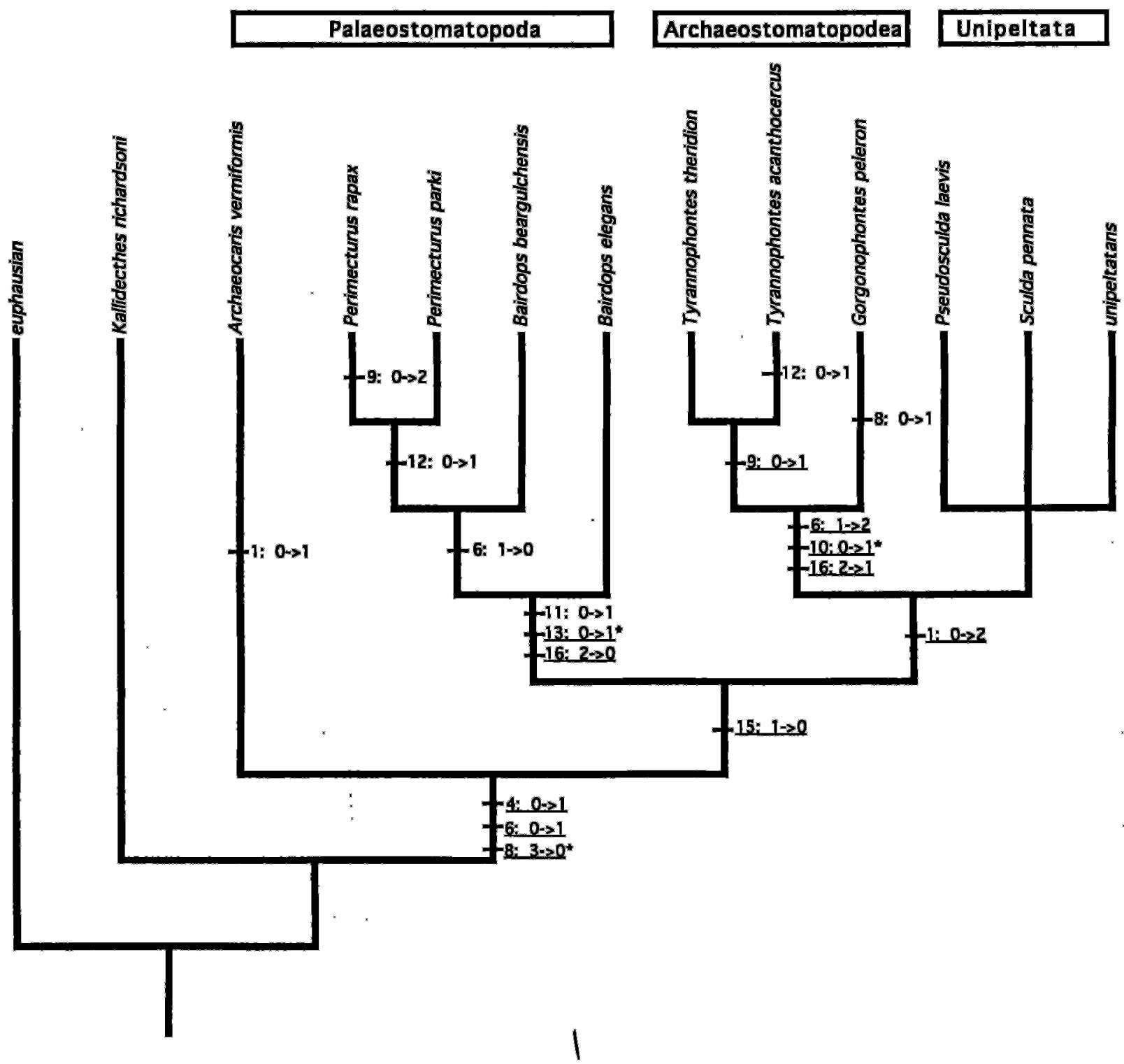

Fig. 7. Strict consensus tree with 13 taxa and 16 characters. Unambiguous character state changes are plotted along the branches. Uniquely derived characters uniting two or more taxa (synapomorphies) are underlined. Asterisks indicate that the character state for a particular character is not known in all depicted clade members.

anterior tagma. The next dichotomy separates $A$. vermiformis from the rest of the rapacious forms. This would make the order Palaeostomatopoda a paraphyletic taxon. A. vermiformis contains a series of characters that separate it from the other palaeostomatopods, only one of which is unambiguous. The size of the lateral carapace wings and the roundness of the carapace unite it with the palaeostomatopods, but the lobate uropod rami resemble the situation seen in tyrannophontids. The apparent absence of a dorsal telson ridge sets $A$. vermiformis apart from the other palaeostomatopods and tyrannophontids.

Among the other rapacious taxa in our analysis three terminal clades emerge: a Perimecturus-Bairdops-clade (P-B clade), an archaeostomatopod or tyrannophontid clade ( $\mathrm{T}$ clade), and a unipeltatan clade (U clade). The P-B clade is supported by the possession of reduced uropodal endopods, bladelike exopods, and a large median telson spike. Blade-like uropodal exopods are also present on the fossil unipeltatan Pseudosculda, but the com- 
bination of blade-like exopods with greatly reduced uropodal endopods uniquely characterizes members of the P-B clade., B. elegans splits off as the sister taxon to the other members of the P-B clade with its possession of spined thoracopodal propodi. The perimecturids are distinguished by the possession of armed uropodal exopods (probably movable spines).Although the complex and very similar patterns of abdominal ornament of the perimecturid species supports this clade, body ornament was not included explicitly in the analysis.

The $T$ and the $U$ clades are united by the possession of an anteroposteriorly reduced carapace. The members of the $T$ clade possess spined and pectinate thoracopodal propodi and a small median telson spike. The singular form of the pleopods is shared by at least G. peleron and T, acanthocercus. The exact form of the pleopods in $T$, theridion needs to be addressed by additional studies. The segmentation pattern of the thoracopods of $G$. peleron separates it from members of the genus Tyrannophontes. The subchelae of $G$. peleron hinge on three small segments that attach to a larger proximal segment, while the subchelae of the Tyrannophontes species hinge on two segments that are attached to a larger proximal segment. It would appear, however, that at the very least we can more clearly define the Archaeostomatopodea thusly: carapace extending dorsally to about the fifth thoracomere and laterally to the sixth or seventh thoracomere; large flap-like scaphocerite; thoracomeres distinctly tagmatized into anterior (thoracomeres one to five) and posterior (thoracomeres six through eight) tagma; a relative size ratio of the first pleomere to the eighth thoracomere of 1.1 to 1.4 ; anterior tagma with four pairs of subequal, armed, subchelate thoracopods; biramous pleopods consisting of one well-sclerotized lobate inner ramus and a slender annulate outer ramus; subrectangular telson base tapering to a moderately sized median spike of maximally one fourth the length of the telson base. At this time $T$. theridion does not appear to exhibit such a spike. Telson carinae, if present, define a median crest on the telson. Uropodal protopods with dorsal posterior process, which is only faintly indicated on $T$. theridion, and a ventral basal prolongation. Uropodal rami broadly lobate, usually with setose margins of exopod (median part) and endopod although, again, such setae are not observed on $T$. theridion.

Because the $U$ clade is a trichotomy, strictly speaking no unambiguous character state changes in our limited matrix can be regarded as supporting the clade. However, some character states are unique for the U-clade. Its members possess an anteroposteriorly reduced, dorsoventrally flattened carapace, which is divided in three fields by gastric grooves. At least Pseudosculda and the group "unipeltatans" possess a pair of very enlarged thoracopods.

The data set contains enough information to sort out the relationships of the larger groups (palaeostomatopods, archaeostomatopods, aeschronectids, unipeltatans including Sculda and Pseudosculda), but this data base does not provide enough resolution for the elucidation of relationships within the unipeltatans. This would require a larger data matrix at least on the level of the unipeltatan superfamilies, or families or genera, to accommodate character polymorphism on higher taxonomic levels (see Hof, in press).

It would appear, however, that the palaeostomatopods delineate a grade of organization rather than a true clade, with separate P-B and Archaeocaris clades. Our cladistic analysis suggests, therefore, that our concepts of the higher taxonomy of the Hoplocarida needs revision. We see two major divisions of the Hoplocarida in Fig. 7: the Aeschronectida, and the line of stem-group rapacious forms leading to the crown group Unipeltata. We could possibly call this rapacious line the Stomatopoda sensu lato, broadening the definition of that name. Under this scheme, we could then recognize a Plesion Archaeocaris and three suborders: Palaeostomatopodea sensu stricto (= Family Perimecturidae), Archaeostomatopodea, and Unipeltata. Purists might object to this redefinition of Stomatopoda and prefer to maintain that name in its traditional sense to link the suborders Archaeostomatopodea and Unipeltata. In that case, we would need to create a new name for a superordinal clade of "carnocarids" that is the sister group to the Aeschronectida.

We hesitate to do anything formally at this time. As this paper points out, there are specific questions that need to be addressed concerning the spe- 


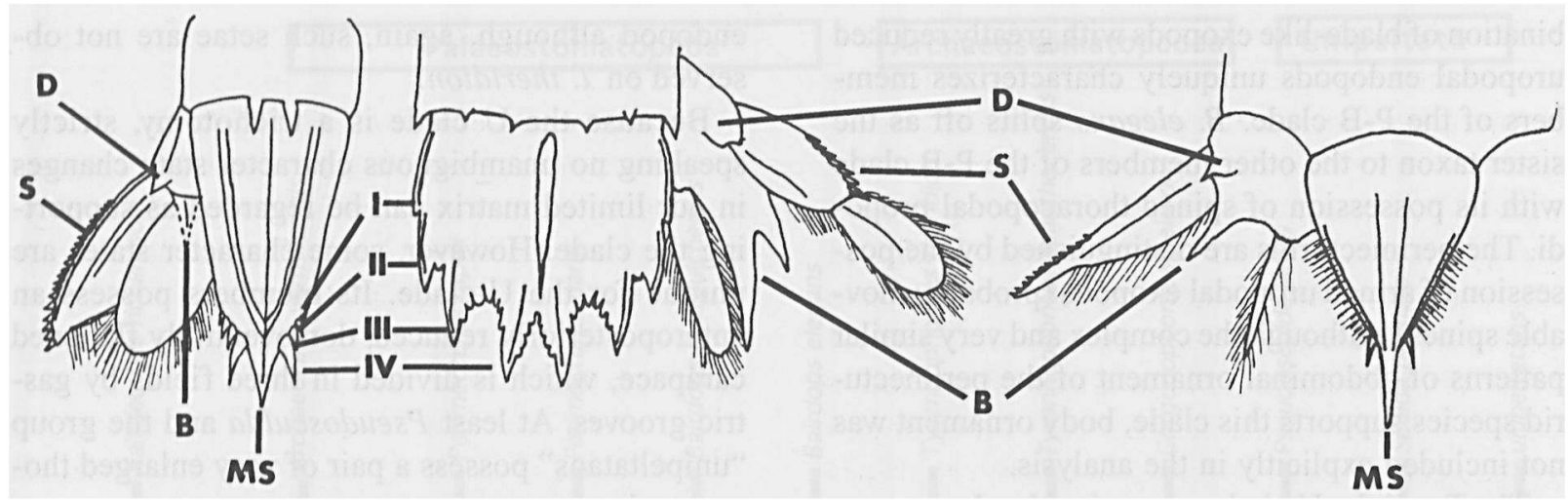

Fig. 8. Schematic tailfan representations of the archaeostomatopod Tyrannophontes acanthocercus (left), a unipeltatan stomatopod Squilla sp. (middle) and the palaeostomatopod Perimecturus parki (right). Possible homologies are indicated. Roman numerals connote possible homologous telson ornaments on the archaeostomatopod and unipeltatan. $\mathrm{B}=$ basal prolongation of forked process on uropodal protopod, $\mathrm{D}=$ dorsal process on uropodal protopod, $\mathrm{MS}=$ median spike, $\mathrm{S}=$ spines on uropodal exopod.

cies of the genus Perimecturus and the species $B$. elegans. For example, at present four of the six known species of palaeostomatopods are placed in a single family, Perimecturidae, but even superficial differences between the dorsoventrally flattened Perimecturus and the more cylindrical species of Bairdops would warrant separate family status. In addition, there are other uncertainties concerning the anatomy of the British forms that must be addressed. Someone should also undertake a careful study of all the available material now in museums and private collections of T. theridion from the Mazon Creek faunas. Finally, given the uncertainties about our knowledge of the details of anatomy of Archaeocaris species, these too should be restudied, since it is still possible that apomorphies unite this genus with the palaeostomatopods sensu stricto.

Our analysis of the phylogeny of the hoplocaridans suggests some intriguing possibilities concerning homologies of anatomical structures between different groups, in particular features of the tail fan. The aeschronectids have very simple, undecorated, uropodal protopods. The rapacious forms acquire a very distinct organization. The palaeo- and archaeostomatopods have uropodal protopods with a small dorsal projection and a larger ventral projection or broad prolongation. The unipeltatans retain the basic arrangement with some elaborations. Usually they possess a bifurcated basal prolongation or forked process.
Another consistent feature of all unipeltatans since the Mesozoic is the possession of spines on the outer margin of the uropodal exopod. Not all palaeo- and archaeostomatopods possess such ornaments. However, where they are present, the spines continue to the distal tip of the 1-segmented uropodal exopod (e.g., Perimecturus and T. acanthocercus). This holds true also for Sculda and Pseudosculda. The other unipeltatans possess 2segmented uropodal exopods with spines confined to the proximal segment (except some members of the superfamily Bathysquilloidea, which have 1segmented uropodal exopods) (Fig. 8). However, the uropodal exopod spines of palaeostomatopods and stomatopods may have independently evolved, as is suggested by the cladogram.

The prominent feature of the stem-group rapacious taxa is a telson bearing a terminal spike. This spike is flanked in the palaeostomatopods by a single pair of furca, but in the archaeostomatopods by four sets of furca. The unipeltatan telson at first glance has a very different form from the above with a broad width, no median terminal spike (indeed a posterior median excavation often bearing denticles), and four pairs of variously developed teeth: submedian, intermedian, lateral, and pre-lateral. It is tempting to see possible homologies between the four sets of furca of Tyrannophontes and the four teeth of unipeltatans. The issue of course is never so straightforward. Unipeltatans display an incredible amount of variation in the telson deco- 
ration both within and between the recognized superfamilies. However, some useful information can be brought to bear on this issue of tail fan homologies from careful consideration of the form, location, and orientation of carinal ornament among all groups, fossil and recent, as well as elucidation and documentation of the anatomy of the Mesozoic genera Sculda and Pseudosculda (Hof, in prep.). What is important to note in all of this is how a careful analysis of characters in a rigorous phylogenetic context can not only provide us hypotheses of relationships, but also focus future lines of research on new or poorly known forms.

\section{Conclusions}

An important result of the present study concerns the increased coherence of the clade that includes the palaeostomatopods and stomatopods. However, the apparent paraphyly of the palaeostomatopods must be tempered in the hopes of some more complete knowledge in the future concerning the characters of Archaeocaris.

The description of Tyrannophontes acanthocercus and the new observations concerning $T$. theridion from the Mazon Creek and Gorgonophontes peleron from the black shales of Nebraska allow a more accurate formulation of a diagnosis of the archaeostomatopods.

We present a proper description of Bairdops beargulchensis as a genuine palaeostomatopod. Bairdops beargulchensis is obviously closely allied to $B$. elegans from the Glencartholm fauna of Scotland, and the definition of all these taxa allows us to generalize about the palaeostomatopods as a group. While Perimecturus and Bairdops are very similar to each other, Archaeocaris has an apparently aberrant morphology. Taken together, the palaeostomatopods possess an array of characters that might be better viewed as a part of a stem-group transition series along with the tyrannophontids, leading to the crown-group unipeltatan stomatopods.

A rigorous phylogenetic framework is now al* lowing us to begin to understand the evolutionary history of the hoplocarids.

\section{Acknowledgements}

We wish to extend special thanks to Dr. Giorgio Teruzzi of the Milan Museum for bringing their collection to our attention and arranging a loan of the material. Without his original stimulus, we would not have undertaken this project.

\section{References}

Allison, P.A., 1988a. Konservat-Lagerstătten: cause and classification. Paleobiology, 14: 331-344.

Allison, P.A., 1988b. The decay and mineralization of proteinaceous macrofossils. Paleobiology, 14: 139-154.

Allison, P.A. \& D.E.G. Briggs, 1991. Taphonomy of nonmineralized tíssues. In: P.A. Allison \& D.E.G. Briggs (eds.), Taphonomy: releasing the data locked in the fossil record: 25-70 (Plenum Press, New York).

Briggs, D.E.G. \& E.N.K. Clarkson, 1985. Malacostracan Crustacea from the Dinantian of Foulden, Berwickshire, Scotland. Trans. R. Soc. Edinburgh Earth Sci., 76: 35-40.

Briggs, D.E.G. \& E.N.K. Clarkson, 1989. Environmental controls on the taphonomy and distribution of Carboniferous malacostracan crustaceans. Trans. R. Soc. Edinburgh, Earth Sci., 80: 293-301.

Briggs, D.E.G. \& E.N.K. Clarkson, 1990. The late Palaeozoic radiation of malacostracan crustaceans. In: P.D. Taylor \& G.P. Larwood (eds.), Major evolutionary radiations. Systematics Association Special Volume, 42: 165-186 (Clarendon Press, Oxford).

Briggs, D.E.G. \& J.-C. Gall, 1990. The contimum in softbodied biotas from transitional environments: a quantitative comparison of Triassic and Carboniferous KonservatLagerstätten. Paleobiology, 16: 204-218.

Briggs, D.E.G. \& A.J. Kear, 1994. Decay and mineralization of shrimps, Palaios, 9: 431-456.

Brooks, H.K., 1962. The Paleozoic Eumalacostraca of North America. Bull. Amer. Paleo., 44: 163-338.

Brooks, H.K, 1969. Palaeostomatopoda. In: R.C. Moore \& C. Teichert (eds.), Treatise on Invertebrate Paleontology, Part R, Arthropoda 4: R533-R535 (Geological Society of America and University of Kansas Press, Lawrence).

Burrows, M., 1969. The mechanics and neural control of the prey capture strike in the mantid shrimps Squilla and Hemisquilla. Z. vergl. Physiol., 62: 361-381.

Calman, W.T., 1904. On the classification of the Crustacea Malacostraca. Ann. Mag. nat. Hist., (7)13; 144-158.

Conway Morris, S., 1990. Typhloesus wellsi (Melton \& Scott 1973), a bizarre metazoan form the Carboniferous of Montana, USA. Phil. Trans. R. Soc. London, (B), 327: 595-624.

Dames, W.B., 1886. Über einige Crustaceen aus den Kreideablagerungen des Libanon. Z. dt. geol. Ges., 38: 551575.

Fabricius, J.C., 1781. Specíes Insectorum exhibentes eorum differentias specificas, synonyma auctorum, loca nata- 
lia, metamorphosin; adiectis observationibus, descriptionibus, 1:1-552 (Bohn, Hamburgi et Kilonii).

Factor, D.F. \& R.M. Feldmann, 1985. Systematícs and paleoecology of malacostracan arthropods in the Bear Gulch limestone (Namurian) of Central Montana. Ann. Carnegie Mus., 54: 319-356.

Hof, C.H.J., in press. Fossil stomatopods and their phylogenetic impact. J, nat. Hist.

Hof, C.H.J. \& D.E.G. Briggs, in press. Decay and mineralization of mantis shrimps (Stomatopoda: Crustacea) - a key to their fossil record. Palaios.

Hof, C.H.J. \& F.R.Schram, in press. Stomatopods (Crustacea: Malacostraca) from the Miocene of California. J. Paleontol.

Holthuis, L.B. \& R.B. Manning, 1969. Stomatopoda. In: R.C. Moore \& C. Teichert (eds.), Treatise on invertebrate paleontology, Part R, Arthropoda 4: R535-R552 (Geological Society of America and University of Kansas Press, Lawrence).

Kunze, J.C., 1981. The functional morphology of stomatopod Crustacea. Phil. Trans. R. Soc. London (B), 292: 255328.

Kunze, J.C., 1983. Stomatopoda and the evolution of the Hoplocarida. Crustacean Issues, 1: 165-188.

Latreille, P.A., 1817. Les crustacés, les arachnides et les insectes. In: G. Cuvier, Le règne animal distribué d'après son organisation, pour servir de base à l'histoire naturelle des animaux et d'introduction à l'anatomie comparée, edition 1, part 3: 1-653 (Déterville, Paris).

Latreille, P.A., 1825. Familles naturelles du règne animal, exposées succinctement et dans un ordre analytique, avec l'indication de leurs genres: 1-570 (J. B. Baillière, Paris).

Manning, R.B., 1995. Stomatopod Crustacea of Vietnam: The legacy of Raoul Serène. Crustacean Research, Special Number, 4: 1-339.

Meek, F.B., 1872. Descriptions of new western Paleozoic fossils, mainly from the Cincinnati group of the Lower Silurian Series of Ohio. Proc. Acad. Nat. Sci. Philadelphia, 24: 335-336.

Melton, W.G., 1969. The Bear Gulch fauna from Central Montana. Proc. N. Amer. Paleont. Convention 1969, Part I: $1202-1207$.

Mikulic, D.G., 1990. The arthropod fossil record: biologic and taphonomic controls on its composition. In: S.J. Culver (ed.), Arthropod paleobiology, Short Courses in Paleontology, 3: 1-23.

Moore, R.C., 1969. Hoplocarida. In: R.C. Moore \& C. Teichert (eds.), Treatise on invertebrate paleontology, Part R, Arthropoda 4: R533 (Geological Society of America and University of Kansas Press, Lawrence).

Olson, E.C., 1966. Community evolution and the origin of mammals. Ecology, 47: 291-302.

Peach, B.N., 1882. On some new Crustacea from the lower Carboniferous rocks of Eskdale and Liddesdale. Trans. $\mathbf{R}$. Soc. Edinburgh, 30: 73-91.

Peach, B.N., 1908. Monograph on the higher Crustacea of the Carboniferous rocks of Scotland. Mem. geol. Surv. Gr. Br. Palaeontol, 1908: 1-91.

Reaka, M.L., 1975. Molting in stomatopod crustaceans. $I$. Stages of the molt cycle, setagenesis, and morphology. $\mathbf{J}_{*}$ Morph., 146: 55-80.

Schram, F.R., 1969. Some Míddle Pennsylvanian Hoplocarida (Crustacea) and their phylogenetic sìgnificance. Fieldiana Geol., 12: 235-289.

Schram, F.R., 1979a. The genus Archaeocaris, and a general review of the Palaeostomatopoda (Hoplocarida: Malacostraca). Trans. San Diego Soc. nat. Hist., 19: 57-66.

Schram, F.R., 1979b. The Mazon Creek biotas in the context of a Carboniferous faunal continuum. In: M.H. Niteckì (ed.), Mazon Creek fossils: 159-190 (Academic Press, New York).

Schram, F.R., 1979c. British Carboniferous Malacostraca. Fieldiana Geol., 40: 1-129.

Schram, F.R., 1981. Late Paleozoic crustacean communities. J. Paleontol, 55: 126-137.

Schram, F.R., 1984. Upper Pennsylvanian arthropods from black shales of Iowa and Nebraska. J. Paleontol., 58: 197209.

Schram, F.R, 1986. Crustacea: 1-606 (Oxford Univ. Press, New York).

Schram, F.R., \& C.H.J. Hof, in press. Fossil taxa and the relationships of major crustacean groups. In: G. Edgecomb (ed.), Arthropod fossils and phylogeny (Columbia Univ. Press, New York).

Schram, F.R. \& J. Horner, 1978. Crustacea of the Mississipian Bear Gulch limestone of central Montana. J. Paleontol., 52: 394-406.

Wilkinson, M., 1995. Coping with abundant missing entries in phylogenetic inference using parsimony. Syst. Biol., 44: 501-514.

Williams, L.A., 1981. The sedimentational history of the Bear Gulch Limestone (Middle Carboniferous central Montana): an explanation of "How them fish swam between them rocks.": 1-252 (Unpublished Ph.D. thesis, Princeton Univ., New Jersey).

Williams, L.A., 1983. Deposition of the Bear Gulch Limestone: a Carboniferous Plattenkalk from Central Montana. Sedimentology, 30: 843-860.

Received: 17 July 1997

\section{Appendix}

\section{Annotated character list}

1 Anterior-posterior carapace extent

$0=$ (almost) complete thorax covering

$1=$ dorsal a deep indentation to expose tergites of posterior thoracomeres

$2=$ thoracomeres 6-8 uncovered 
2 Carapace roundedness

$0=$ rounded carapace which envelops the cephalon and thorax (thoracopod coxae may protrude from underneath the carapace)

$1=$ flattened (dorsoventrally) carapace

3 Carapace fields

$0=$ no fields

$1=$ carapace tripartitioned by gastric grooves

4 Thorax tagmata (defined by segment and/or appendage differentiation)

$0=$ tagmata absent

$1=$ anterior tagma with subchelate thoracopods and posterior tagma of larger segments with non-subchelate appendages

5 Relative size subchelate thoracopods

$0=$ (sub)equal thoracopods

$1=$ one pair very enlarged

6 Propodus second thoracopod

$0=$ smooth margin

$1=$ spined margin

$2=$ pectinate and spined

$3=$ pectinate

Pectinate refers to the possession of closely apposed (no interspaces) short and relatively blunt spines, while spined refers to the possession of slender, sharp spines that may be movable.

7 Dactylus second thoracopod

$0=$ smooth

$1=$ spined

8 Conformation second thoracopod

$0=$ subchela hinged on 2 segments

$1=$ subchela hinged on 3 segments

$2=$ subchela hinged on 1 segment

$3=$ achelate thoracopods
9 Pleural spines

$0=$ absent

$1=$ on pleomeres $3-6$

$2=$ on all pleomeres

$3=$ on pleomere 6

Pleural spines are sharp protrusions, posteriorly or posteroventrally directed from the ventral margins of the abdominal pleurae.

10 Pleopod form

$0=$ simple flap-like rami

$1=$ annulate, slender outer ramus, robust, lobate inner ramus

11 Uropod, exopod form

$0=$ lobate, 1 -segmented

1 = blade-like, 1 -segmented

2 = 2-segmented

12 Uropod, exopod decoration

$0=$ smooth outer margin

$1=$ armed outer margin (spines, serration)

13 Uropod, endopod form

$0=$ simple, lobate

$1=$ reduced with a pointed tip

14 Uropod, protopod form

$0=$ smooth

$1=$ dorsal and ventral protrusions or processes present

15 Telson crest or ridge

$0=$ longitudinal dorsal median crest or ridge present on the telson

$1=$ absent

16 Median telson spike

$0=$ spike a third or more the length of the telson base

$1=$ spike a fourth or less the length of the telson base

$2=$ absent 